\title{
Critical Shields values in coarse-bedded steep streams
}

\author{
Kristin Bunte, ${ }^{1}$ Steven R. Abt, ${ }^{1}$ Kurt W. Swingle, ${ }^{2}$ Dan A. Cenderelli, ${ }^{3}$ \\ and Johannes M. Schneider ${ }^{4}$
}

Received 13 July 2012; revised 24 September 2013; accepted 2 October 2013; published 18 November 2013.

[1] Critical Shields values $\left(\tau_{c}^{*}\right)$ suitable for specific applications are back-calculated from representative bed load samples in mountain streams and a flow competence/critical flow approach. The general increase of $\tau_{c 50}^{*}$ (for the bed $D_{50}$ size) as well as $\tau_{c 16}^{*}$ and $\tau_{c 84}^{*}$ (for the bed $D_{16}$ and $D_{84}$ sizes) with stream gradient $S_{x}$ and also the stratification of $\tau_{c 50}^{*}$ by relative flow depth and relative roughness are confirmed. Critical Shields values $\tau_{c 16}^{*}$ are shown to exceed $\tau_{c 50}^{*}$ by about threefold, while those for $\tau_{c 84}^{*}$ are nearly half of $\tau_{c 50}^{*}$. However, it remains unclear to what extent physical processes or numerical artifacts contribute to determining critical Shields values. Critical bankfull Shields values $\left(\tau_{c b f}^{*}\right)$ back-computed from the average largest particles mobile at bankfull flow $D_{B m a x, b f}$ approach $\tau_{c 16}^{*}$ at steep gradients and $\tau_{c 84}^{*}$ at low gradients and therefore increase very steeply with $S_{x}$. The relation $\tau_{c b f}^{*}=f\left(S_{x}\right)$ is stratified by bed stability $\left(D_{50} / D_{B m a x, b f}\right)$ and predictable if bed stability can be field categorized. Noncritical Shields values $\left(\tau_{b f 50}^{*}\right)$ computed from bankfull flow depth and the $D_{50}$ size differ from $\tau_{c 50}^{*}$ and $\tau_{c b f}^{*}$. Only in bankfull mobile streams where $D_{50} /$ $D_{B \max }=1 \operatorname{can} \tau_{c b f}^{*}, \tau_{c 50}^{*}$, and $\tau_{b f 50}^{*}$ be used interchangeably. In highly mobile streams, substituting $\tau_{c b f}^{*}$ by $\tau_{b f 50}^{*}$ overpredicts the $D_{B m a x, b f}$ size by up to fivefold and underpredicts $D_{B m a x, b f}$ by the same amount in highly stable streams. A value of 0.03 is appropriate for $\tau_{c b f}^{*}$ only on low stability beds with $S_{x} \cong 0.01$, but overpredicts $D_{B \max , b f}$ by 30 -fold on highly stable beds with $S_{x} \cong 0.1$. Differences in field and computational methods also affect critical Shields values.

Citation: Bunte, K., S. R. Abt, K. W. Swingle, D. A. Cenderelli, and J. M. Schneider (2013), Critical Shields values in coarse-bedded steep streams, Water Resour. Res., 49, 7427-7447, doi:10.1002/2012WR012672.

\section{Introduction}

[2] Estimating the largest bed material particle size mobile at a specified flow in coarse-bedded steep streams is a common task in many geomorphological environments and for various engineering problems, and the Shields equation is commonly employed for this purpose. A wide variety of Shields-type parameters that differ in computational details and numerical values have been proposed for steep and coarse-grained channels. However, there is not much guidance as to which values should be selected for a specific purpose, and large errors may result when critical particle size or critical flow is computed from an inappropriate Shields value. It is the aim of this empirically oriented study to improve user choices for selecting appropriate crit-

\footnotetext{
${ }^{1}$ Engineering Research Center, Colorado State University, Fort Collins, Colorado, USA.

${ }^{2} 630$ Iris Avenue, Boulder, Colorado, USA

${ }^{3}$ Watershed, Fish, Wildlife, Air, \& Rare Plants Staff, Stream Systems Technology Center, USDA Forest Service, Fort Collins, Colorado, USA.

${ }^{4}$ Swiss Federal Institute for Forest, Snow and Landscape Research, WSL, Mountain Hydrology and Mass Movements, Birmensdorf, The Canton of Zurich, Switzerland.
}

${ }^{*}$ Corresponding author: K. Bunte, Engineering Research Center, Colorado State University, 1320 Campus Delivery, Fort Collins, CO 80523, USA. (kbunte@engr.colostate.edu)

(C)2013. American Geophysical Union. All Rights Reserved. 0043-1397/13/10.1002/2012WR012672 ical Shields values for use in steep channels. The study further aims to alert the user to differences among various Shields-type parameters and to provide choices for critical Shields values for bankfull flow.

[3] The Shields equation is based on flume experiments in which Shields [1936] quantified the critical dimensionless shear stress $\tau_{c D m}^{*}$ as the numerical value of the term:

$$
\tau_{c D m}^{*}=\frac{\rho_{f} \cdot g \cdot R_{c} \cdot S_{f}}{\left(\rho_{s}-\rho_{f}\right) \cdot g \cdot D_{m}}=\frac{\rho_{f}}{\rho_{s}-\rho_{f}} \cdot \frac{R_{c} \cdot S_{f}}{D_{m}}
$$

at incipient motion of rounded to angular particles from relatively well-sorted beds with a specified $D_{m}$ size in the absence of bed forms; $\rho_{f}$ and $\rho_{s}$ denote the water and sediment densities, $g$ is acceleration due to gravity, $R_{c}$ is the hydraulic radius at incipient motion of $D_{m}, D_{m}$ is the mean bed material particle size that in well-sorted distributions is similar to the median $\left(D_{50}\right)$ size, and $S_{f}$ is the friction gradient which under conditions of uniform flow is similar to the channel bed gradient $S_{x}$ that is typically determined along the channel waterlines. Shields [1936] presented $\tau_{c D m}^{*}$ values in relation to the particle Reynolds number ${ }^{R} e_{p}=\left(g \cdot R_{c} \cdot S\right)^{0.5} \cdot D_{m} / v$ that is controlled mainly by $D_{m}$ and secondly by $S_{\mathrm{x}}$ which covers a much wider range among the study streams than $R_{c} ; \nu$ is kinematic viscosity that decreases with water temperature $T_{w}$ from $1.5 \cdot 10^{-6}$ to $1.0 \cdot 10^{-6} \mathrm{~m}^{2} / \mathrm{s}$ for $T_{w}$ from 5 to $20^{\circ} \mathrm{C}$. Shields' [1936] flume experiments employed beds with 


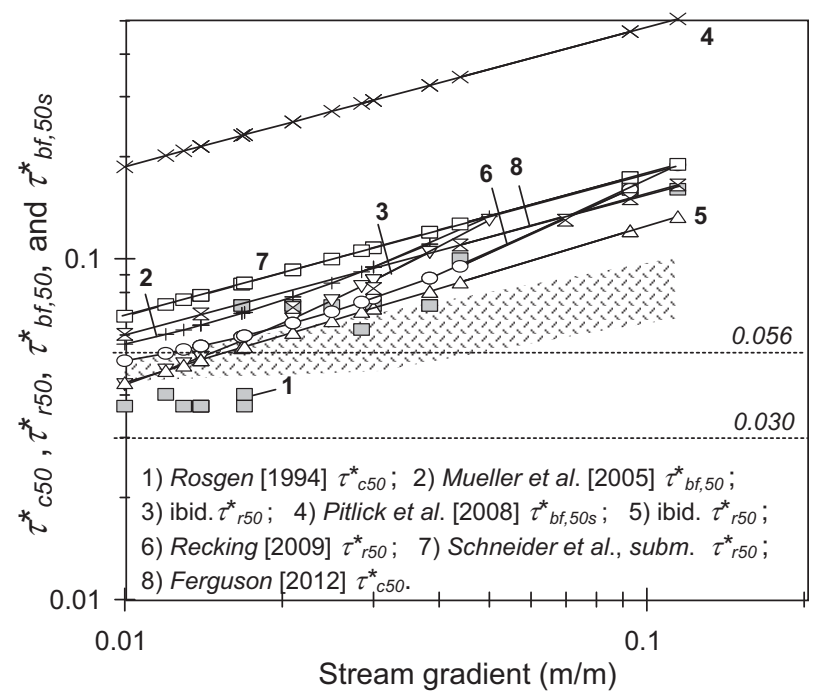

Figure 1. Empirical and modeled [Recking, 2009; Ferguson, 2012 (for $D_{84} / D_{50}=2$ )] relations of $\tau_{c 50}^{*}, \tau_{r 50}^{*}, \tau_{b f, 50}^{*}$, and $\tau_{b f .50 \text { sub }}^{*}$ with gradient in steep streams compiled from multiple sources. $\tau_{c 50}^{*}$ is the critical Shields value for the bed $D_{50}$ size; $\tau_{r 50}^{*}$ refers to the reference transport method not discussed here; $\tau_{b f, 50}^{*}$ and $\tau_{b f, 50 s u b}^{*}$ refer to non-critical Shields values computed from bankfull flow hydraulics and the bed surface $D_{50}$ and subsurface size $D_{50 \text { sub }}$, respectively. For clarity of the figure, flume-derived relations $\tau_{c 50}^{*}=f\left(S_{x}\right)[$ Bathurst et al., 1983, 1987; Shvidchenko and Pender, 2000; Lamb et al., 2008; Parker et al., 2011] are not plotted individually but contained within the shaded area.

rather uniformly sized particles of less than $4 \mathrm{~mm}$ and ended near $R e_{p}=500$, but he (and especially later researchers) assumed that the nonmonotonic, spoon-shaped curve $\tau_{c}^{*}=f\left(R e_{p}\right)$ approaches a constant value of $\tau_{c D m}^{*}=0.056$ for $R e_{p}$ much larger than 500, extending the Shields relationship considerably beyond its original range. With application of the Shields equation to natural streams where the central tendency of the bed material particle-size distribution is better characterized by the median $\left(D_{50}\right)$ than the mean $\left(D_{m}\right)$ due to the distribution skewness, the critical Shields value at incipient motion of the bed $D_{50}$ size (a.k.a. Shields stress) became denoted as $\tau_{c 50}^{*}$. In this study, the terms Shields value or Shields number refers to the critical value at incipient motion unless otherwise noted.

[4] Subsequent redrawings and analytical expressions of the Shields curve as well as additional experiments [Rouse, 1939; Meyer-Peter and Müller, 1948; Vanoni et al., 1966; Neill, 1968; Paintal, 1971; Miller et al., 1977; Yalin and Karahan, 1979; Brownlie 1981; Parker et al., 2003] suggested that $\tau_{c}^{*}$ values for $R e_{p}>500$ range within $0.03-0.06$, rather than being the single value of 0.056 proposed by Shields. This variability invalidates the assumption of a unique relation $\tau_{c}^{*}=f\left(R e_{p}\right)$, a requirement, if the Shields equation (equation (1)) is to be solved for either $R_{c}, S_{x}$, or $D_{50}$. Shields values compiled by Buffington and Montgomery [1997] extended over an even wider range from 0.01 to 0.09 in coarse-bedded steep streams where $R e_{p}$ takes values within 4000-100000. Buffington and Montgomery [1997] attribute the variability to differences in bed stability (or bed mobility) as well as computations and field methods. Many previous and later studies have shown that Shields values are affected by whether bed particles are loose and easily mobilized or restrained by bed structures and by particle interlock. Particle entrainment has been reported to be affected by particle imbrication [Komar and Li, 1986; Gordon et al., 1992], by different particle shapes [ $L i$ and Komar, 1986], the presence of particle clusters [Brayshaw et al., 1983], by particle hiding and protrusion, bed sorting, pocket, and pivot angles [Isbash, 1936; White, 1940; Fenton and Abbott, 1977; Parker et al., 1982; Andrews, 1983; Fisher et al., 1983; Wiberg and Smith, 1987; Kirchner et al., 1990; Andrews and Smith, 1992; Carling et al., 1992; Andrews, 1994; Ferguson, 2012]; by packing density [Gordon et al., 1992], stone structures [Church et al., 1998; Hassan and Church, 2000], as well as by antecedent flow and bed conditions [e.g., Gomez, 1983; Reid et al., 1985; Beschta, 1987; Turowski et al., 2011]. An increasingly wider range of Shields values from $<0.03$ to $>0.5$ has been reported for steep channels [Bathurst et al., 1983, 1987; Lepp et al., 1993; Rosgen, 1994, 1996; Shvidchenko and Pender, 2000; Buffington and Montgomery, 2001; Buffington et al., 2004, 2006; Zimmermann et al., 2010; Bunte et al., 2010a; Comiti and Mao, 2012]. Finally, various flume, modeling, and field studies have shown that Shields values for the bed $D_{50}$ size increase with stream gradient $S_{x}$ in coarse-bedded steep streams as shown in Figure 1 [Shvidchenko and Pender, 2000; Mueller et al., 2005, Buffington et al., 2006; Parker et al., 2011; Pitlick et al., 2008; Lamb et al., 2008; Recking, 2009; Camenen, 2012; Comiti and Mao, 2012; Buffington, 2012; Ferguson, 2012; Bunte, 2012a; Recking and Pitlick, 2013; J. M. Schneider et al., Field data based bed load transport prediction for mixed size sediments, submitted to WRR, 2013]. The reported correlation of Shields values with $S_{x}$ offers an opportunity for prediction of Shields values. However, individual relations of Shields values versus $S_{x}$ likewise involve scatter, and the proposed relations differ among studies as presented in Figure 1. The inter-study variability in relations of $\tau_{c}^{*}=f\left(S_{x}\right)$ is attributable not only to differences in stream conditions (structural bed stability, bed material size composition, sediment supply, flow hydraulics, and stream morphology), but also to methodological and computational diversity. Field measurements of $S_{x}, D_{50}, Q$, $d$, and $R$ may differ among studies, but differences are typically less than a factor of 2 . Possibly larger variations result from methodological differences for quantifying particle entrainment in the field [Wilcock, 1988]: there is a direct, field-based flow competence approach in which either the average or the absolute largest bed load particle size $D_{B \max }$ mobile at a specific flow is quantified from repeated bed load samples or from tracer particles (largest grain method), and a relation of critical flows versus entrained particle sizes is established. For this approach, the emplacement depth and location of tracer particles as well as the ability of a sampling device to representatively include the largest mobile particle sizes, the sampling time, and sampling frequency become important. The "small transport method" quantifies critical flow as the flow at which a preset (low) transport rate (typically computed rather than measured) is exceeded for a specified size class using, for example, the reference transport rate approach introduced 
by Parker et al. [1982] (not discussed here). Apart from scatter and between-study variability in the reported relation of $\tau_{c}^{*}$ versus $S_{x}$, another challenge concerning use of the Shields approach is its (mis-) application to predict the largest particle size mobile at bankfull flow in coarsebedded streams. In this context, bankfull flow is broadly considered as the flow that inundates point bars and lateral bars sufficiently to shape them and extends laterally to the onset of perennial near-bank vegetation. Such flows tend to correspond with the 1.5-2 year recurrence interval flow. Bankfull flow is considered a reference state for high flows [Leopold, 1994; Buffington and Montgomery, 1999; Trush et al., 2000; Parker et al., 2007], and prediction of the largest particle size mobile at bankfull flow $\left(D_{B \max , b f}\right)$ is of interest for restoration projects and for evaluation of streambed stability or mobility. In assessments of the relative bed stability index in gravel/cobble/bed streams, the $D_{50}$ particle size is set in relation to the $D_{B \max , b f}$ size [e.g., Olsen et al., 1997; Kappesser, 2002, Lorang and Hauer, 2003; Kaufmann et al., 2008, 2009]. For $R e_{p}>500$, these applications use a constant Shields value, e.g., 0.03 or 0.056 to compute $D_{B m a x, b f}$. However, the original Shields equation was not developed to predict the particle size mobile at bankfull (or any other) flow. When used to predict $D_{c}$, the Shields equation iteratively determines whether a (near-) uniform bed with a specific mean particle size $\left(D_{m}\right)$ can be mobilized given $R$ and $S_{x}$ (ignoring $\rho_{f}$ and $\rho_{s}$ here). Hence, solving the Shields equation for $D_{c}$ given $R$ and $S_{x}$ cannot accurately predict which of the many particle sizes in a mixed-size bed will become entrained because entrainment depends on the bed material composition and structure, sediment supply, flow hydraulics, and stream morphology. Not knowing which of the bed material sizes can be entrained by a specific flow, it is inappropriate to use the bed $D_{50}$ size to determine the $R e_{p^{-}}$and hence the $\tau_{c}^{*}$-value to be used when solving the Shields equation for the largest mobile particles at bankfull flow $\left(D_{B m a x, b f}\right)$ given $S_{x}$ and $R_{b f}$. This approach presupposes mobility of the bed $D_{50}$ size at bankfull flow. Users often ignore these limitations [e.g., Kaufmann et al., 2008, 2009]. Our study will show that solving equation (1) for $D_{c}$ based on $R_{b f}$ and $S_{x}$ and a Shields value from the curve provides an unbiased estimate of $D_{B m a x, b f}$ only in streams that move their bed $D_{50}$ size at bankfull flow. For the many (frequently steep) streams that do not behave in this manner, application of the Shields equation assuming mobility of the $D_{50}$ size is not correct.

[5] This study employed a direct approach for quantifying particle entrainment. Extensive measurements of gravel bed load particle sizes in various mountain streams were used to quantify relations of critical flow for incipient motion $\left(Q_{c}, d_{c}\right.$, and $\left.R_{c}\right)$ for specified particle sizes as well as critical (i.e., entrained) particle sizes $\left(D_{c}\right)$ for a specified flow for each study stream. Critical Shields values were then back-calculated from those relations. Characterizing relations between $R_{c}$ and $D_{c}$ exclusively from a flow competence approach - as well as its inverse, the critical flow curve - rather than compiling incipient motion information from various sources (e.g., tracer particles, critical flows, and reference transport rates) reduces the inherent methodological variability that may underlie published Shields values. The back-computed critical Shields values $\tau_{c}^{*}$ are then regressed against stream gradient $S_{x}$. Scatter in the relations of $\tau_{c}^{*}=f\left(S_{x}\right)$ is reduced via stratification by relative flow depth $\left(d_{b f} / D_{50}\right)$ and relative bankfull roughness $\left(D_{84} / d_{b f}\right)$, and fitted regression functions provide guidance for prediction of critical Shields values using channel and flow parameters that are relatively easy to obtain. The study presents critical Shields values for the $D_{16}, D_{50}, D_{50 s u b}$, and $D_{84}$ bedmaterial percentile particle sizes as well as for the largest particle sizes $D_{B m a x, b f}$ entrained at bankfull flow $\left(\tau_{c b f}^{*}\right)$ and compares measured critical Shields values $\tau_{c 50}^{*}$ and $\tau_{c b f}^{*}$ with noncritical Shields values derived from bankfull flow and the $D_{50}$ size $\left(\tau_{b f 50}^{*}\right)$. Based on the observed differences in sampling results among bed load samplers [e.g., Bunte et al. 2008, 2010b], Shields values back-computed from bed load traps and similarly suited samplers are compared to those back-computed from the frequently used Helley-Smith [1971] bed load samples. The effects of input parameter error and bias on critical Shields values are also assessed.

\section{Methods}

\subsection{Bed load Measurements of Particle Mobility}

[6] Computations of $\tau_{c}^{*}$ that are based on a flow competence or critical flow approach require bed load transport measurements that accurately represent the largest bed load particle size $D_{B \max }$ mobile at a specified flow [Wilcock, 2001]. In steep streams with unsteady flow and a wide range of bedmaterial particle sizes, those measurements require bed load samplers with large openings and large sample volumes in order to sample over a long time to catch the infrequently moving large particles. In addition, the sampler's interaction with bed particles and ambient flow hydraulics must be minimal. The sampling scheme, i.e., the number of samples taken over a highflow day and across the stream, must be appropriately intense to cover the temporal and lateral variability of bed load transport over the highflow season. With these criteria in mind, bed load traps were designed and deployed in this study to representatively collect $D_{B \max }$ particles [Bunte et al., 2004, 2007, 2008, 2010c; Bunte and Abt, 2005]. Bed load traps have a sampler capacity of about 20 liters. For an individual sample, four to six lateral traps were deployed for $1 \mathrm{~h}$ or more when transport rates were low; during this time fluctuations in discharge were typically low as well. At high transport rates and when snowmelt discharge changed quickly, sampling times were reduced to $30 \mathrm{~min}$, and to as little as $5 \mathrm{~min}$ to avoid overfilling the net when bed load particles were streaming into the sampler.

\subsection{Bed load Data Sets}

[7] Field data used for the computations of Shields values comprised bed load samples collected with bed load traps in 10 Rocky Mountain streams [Bunte et al., 2004, 2008, 2010c, 2011, 2012; Potyondy et al., 2010] and those collected in the Riedbach, a proglacial stream in the Swiss Alps, by Schmid [2011] as well as by J. Schneider (personal communication 2012). Also used were gravel bed load data from studies with other samplers that likely provide representative samples of the rarely moving largest clasts. These samplers include the large $1 \mathrm{~m}^{3}$ perforated moving steel baskets placed under a weir overfall at the Erlenbach torrent in the Swiss Pre-Alps [Rickenmann et al., 2012; J. 
Table 1. Study Site Characteristics

\begin{tabular}{|c|c|c|c|c|c|c|c|c|c|c|c|}
\hline $\begin{array}{l}\text { Stream and Year(s) } \\
\text { Sampled }\end{array}$ & $\begin{array}{c}\mathrm{A} \\
\left(\mathrm{km}^{2}\right)\end{array}$ & $\underset{\left(\mathrm{m}^{3} / \mathrm{s}\right)}{Q_{b k f}}$ & $\begin{array}{l}w_{b f} \\
(\mathrm{~m})\end{array}$ & $\begin{array}{c}S_{x} \\
(\mathrm{~m} / \mathrm{m})\end{array}$ & $\begin{array}{l}d_{b f} \\
(\mathrm{~m})\end{array}$ & $\begin{array}{l}D_{16} \\
(\mathrm{~mm})\end{array}$ & $\begin{array}{l}D_{50} \\
(\mathrm{~mm})\end{array}$ & $\begin{array}{l}D_{84} \\
(\mathrm{~mm})\end{array}$ & $\begin{array}{l}D_{50 s} \\
(\mathrm{~mm})\end{array}$ & $\begin{array}{l}\text { Dominant } \\
\text { Lithology }\end{array}$ & $\begin{array}{l}\text { Dominant } \\
\text { Morphology }\end{array}$ \\
\hline Dupuyer 1995 & 83 & 6.5 & 10 & 0.010 & 0.52 & 16 & 42 & 90 & 37 & Mixed sediments & \multirow{4}{*}{$\begin{array}{l}\text { Mixed plane-bed } \\
\text { and pool riffle }\end{array}$} \\
\hline Little Granite 2002 & 13 & 2.8 & 6.3 & 0.012 & 0.32 & 23 & 67 & 138 & 34 & Mixed sediments & \\
\hline Harris 1991, (3B and 1A) & 220 & 19 & 20 & 0.013 & 0.72 & $9.5^{\mathrm{a}}$ & $48^{\mathrm{a}}$ & 95 & 32 & Gneiss, Basalt & \\
\hline Oak 1969-1971 & 7 & 1.3 & 4.5 & 0.014 & 0.32 & $15^{\mathrm{a}}$ & $49^{\mathrm{a}}$ & $76^{\mathrm{a}}$ & 20 & Volcanic & \\
\hline Halfmoon riffle 2004 & 61 & 6.2 & 8.6 & 0.014 & 0.71 & 14 & 49 & 119 & 26 & Granite, Gneiss & \multirow{7}{*}{$\begin{array}{l}\text { Plane-bed with } \\
\text { isolated,forced } \\
\text { pool-riffle } \\
\text { sequences }\end{array}$} \\
\hline Halfmoon bar 2004 & 61 & 6.2 & 8.6 & 0.014 & 0.55 & 14 & 49 & 119 & 26 & Granite, Gneiss & \\
\hline East Dallas 2007 (high) & 34 & 3.7 & 7.5 & 0.017 & 0.31 & 12 & 57 & 123 & 21 & Andesite, other & \\
\hline East Dallas 2007 (high) & 34 & 3.7 & 7.5 & 0.017 & 0.31 & 16 & 59 & 125 & 21 & volcanic & \\
\hline Little Granite 1999 & 55 & 5.7 & 14.3 & 0.017 & 0.39 & 20 & 59 & 133 & 42 & Mixed sediments & \\
\hline St. Louis 1998 & 34 & 4.0 & 6.5 & 0.017 & 0.38 & 22 & 76 & 163 & 41 & Gneiss, Granite & \\
\hline Squaw 1988 and 1991 & 105 & 5.7 & 11 & 0.021 & 0.33 & 13 & 43 & 99 & 27 & Andesite, Gneiss & \\
\hline Cherry '99 & 41 & 3.1 & 9.5 & 0.025 & 0.42 & 6.4 & 52 & 140 & 27 & $\begin{array}{l}\text { Andesite, other } \\
\text { volcanic }\end{array}$ & \multirow{4}{*}{$\begin{array}{l}\text { Plane-bed } \\
\text { with low } \\
\text { steps }\end{array}$} \\
\hline Riedbach 2011 & 16 & 3.0 & 11 & 0.028 & 0.41 & 7.1 & 56 & 163 & 28 & Gneiss, Schist & \\
\hline NF Swan 2011 (high) & 16 & 1.3 & 5.6 & 0.030 & 0.23 & 7.6 & 39 & 124 & 22 & Gneiss, Schist & \\
\hline NF Swan 2011 (low) & 16 & 1.3 & 5.6 & 0.030 & 0.23 & 5.8 & 52 & 132 & 22 & Gneiss, Schist & \\
\hline Hayden 2005 (low \& high) & 40 & 1.9 & 7.0 & 0.038 & 0.26 & 14 & 63 & 164 & 36 & Mixed sediments & \multirow{4}{*}{ Step-pool } \\
\hline Fool 2009 and 2010 & 3 & 0.3 & 1.3 & 0.044 & 0.20 & 12 & 52 & 122 & 25 & Gneiss, schist & \\
\hline $\begin{array}{l}\text { E. St. Louis '01 (high), } \\
\text { E. St. Louis } 2003 \text { (low) }\end{array}$ & 8 & 0.8 & 3.7 & 0.093 & 0.44 & 15 & 108 & 258 & 54 & Gneiss, schist & \\
\hline Erlenbach 2009-2011 & 0.8 & 1.5 & 3.7 & 0.105 & 0.31 & 8.7 & 64 & 215 & 27 & Mixed sediments & \\
\hline
\end{tabular}

${ }^{\text {a}}$ Estimated. Descriptions (low) and (high) refers to relatively low and high sediment supply.

Turowski and D. Rickenmann, personal communication 2012] and the large net-frame samplers at Squaw Creek, SW Montana [Bunte, 1996] and at Dupuyer Creek, NW Montana [Whitaker, 1997; Whitaker and Potts, 1996, 2007a, 2007b], the vortex sampler at Oak Creek, NW Oregon [Milhous, 1973], and nonweighing pit traps (locations 3B and 1A) at Harris Creek in British Columbia [Hassan and Church, 2000, 2001; Church and Hassan, 2002].

[8] The characteristics of all study sites are presented in Table 1. Most of the study streams are located in the US Rocky Mountains, some are located in other mountain ranges of the Western US and Canada and in the Swiss Alps. Except for the pristine Riedbach, study watersheds have experienced some logging, roading, mining, or direct stream management, but are not considered notably impaired. All sites have snowmelt regimes except Oak Cr. and Erlenbach which have pluvio-nival regimes and Riedbach which has a glacial-nival regime. As is typical of steep Rocky Mountain streams, channels are incised into a vegetated and morphologically largely inactive floodplain, and flows of $150 \%$ of bankfull (i.e., $150 \%$ the 1.5 or 2 year recurrence interval) cause only minor overbank spill.

[9] At most of the authors' bed load trap study sites, bed load was also collected using a " 3 inch" ( 7.6 by $7.6 \mathrm{~cm})$ opening size sheet-metal Helley-Smith (HS) sampler with a standard $0.25 \mathrm{~mm}$ mesh bag, placing the HS sampler directly onto the bed at 15-20 locations across the stream for 2 min per location or less if the bag filled. Typically, fewer samples were collected with a Helley-Smith sampler (HS) than with bed load traps during a field season. At sites where the authors' HS samples fit well within the larger data sets of HS samples collected by Ryan et al. [2005] at the same site or nearby, the two sets of HS samples were combined to improve the flow competence/critical flow relations fitted to HS data sets. Because bed load traps are designed to collect particles $>4 \mathrm{~mm}$, all sediment $<4 \mathrm{~mm}$ was mathematically removed from the Helley-Smith samples such that only gravel bed load of particle sizes $>4 \mathrm{~mm}$ is compared for both samplers.

[10] A change in steepness of bed load transport $\left(Q_{b}\right)$ rating curves, often between rising and falling limbs of the high flow season (hysteresis), is a known phenomenon [e.g. Beschta, 1987; Bunte and MacDonald, 1999; Mao, 2012]. Changes in the steepness of flow competence curves within and between events can likewise occur [Mao, 2012; Swingle et al., 2012]. In two of the authors' bed load trap study streams, the flow competence relation changed during the high flow season. At North Fork (NF) Swan Cr., $D_{B \max }$ sizes dropped abruptly before peakflow when a beaver dam intercepted upstream sediment supply [Bunte et al., 2011] as presented in Figure 2. At Hayden Creek, $D_{B \max }$ sizes decreased considerably after peakflow, likely due to upstream particle entrapment. At Squaw Cr. and East St. Louis Cr., flow competence and critical flow relations differed between years of repeated sampling [see also Turowski et al., 2011], and at Halfmoon Cr., flow competence curves diverged between two neighboring sampling locations (riffle and bar site). Because changes in the flow competence/critical flow relation are brought about by changes in sediment supply and particle mobility, which are likewise reflected in critical Shields values $\tau_{c}^{*}$ back-calculated from field data, separate regressions were fitted to sites where changes in the flow competence relation were observed. Altogether, 22 data sets were compiled from these coarse-bedded steep streams. The typically wider data scatter of the HS data did not permit segregation within a highflow period, among neighboring sites, or between years. As a result, there is only one HS data set per site.

\subsection{Quantification of Bed Material Particle Sizes, Stream Gradient, and Discharge}

[11] At almost all of the bed load trap study sites as well as at the Erlenbach, bed material $D_{50}$ sizes were quantified 


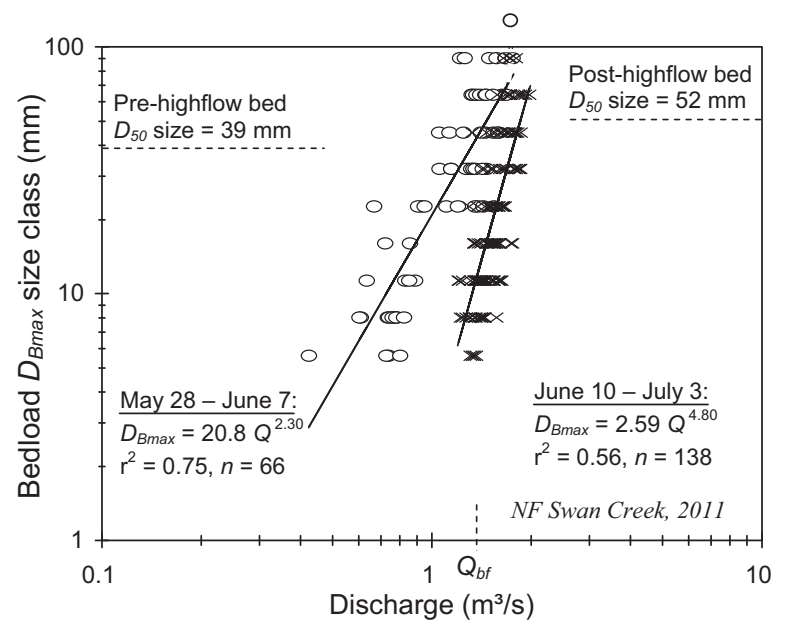

Figure 2. Examples of flow competence relations at North Fork Swan Creek, 2011 not available in Bunte et al. [2004, 2008, 2010c, 2011] or Potyondy et al. [2010]. Field data are segregated into two parts, one for the beginning of the highflows season and one during the highflow season when the site experienced a depletion of sediment supply due to sediment retained in an upstream beaver dam.

from reach-spanning pebble counts using the SFT procedure [Bunte et al., 2009] that minimizes observer bias and samples $400+$ particles within the bankfull channel. Subsurface $D_{50 \text { sub }}$ sizes were obtained from 2 to 3 large volumetric samples of the subsurface sediment (sand included) with a joint weight of 200-300 kg. The subsurface samples were collected on riffles and runs under water within a 0.6 by $0.6 \mathrm{~m}$ plywood shield enclosure after removal of surface particles [Bunte and Abt, 2001a]. All particle sizes, i.e., surface and subsurface sediment as well as the bed load $D_{B \max }$ sizes were quantified using a square-hole sieve stack or a template with opening sizes progressing in $0.5 \phi$. At East Dallas and NF Swan Creeks, bed material was sampled before and after changes in sediment supply. The remaining studies employed other sampling techniques. Drawing upon the text or photos, as well as information obtained from other studies conducted at or near the same site, reported bed material data were converted or adjusted to align with an SFT pebble count or a large subsurface sample. For example, Milhous [1973] obtained the bed $D_{50}$ size originally from volumetric armor samples that were converted to grid-by-number samples [Kellerhals and Bray, 1971]. Hassan and Church [2000, 2001] and Church and Hassan [2002] determined the surface $D_{50}$ size from a pebble count truncated at $2 \mathrm{~mm}$, while reporting the presence of sand on the bed. To compare only untruncated distributions, a sand portion slightly smaller than that reported for the subsurface was mathematically added to the surface sediment, and the size distribution was recalculated.

[12] Stream gradient $S_{x}$ in the bed load trap study streams was determined as the arithmetic mean of the gradients computed from longitudinal profiles surveyed along both waterlines at low or moderate flows over reach lengths of 7-12 stream widths $(w)$, hence $S_{x}$ denotes a reach-averaged value. At most of the study streams, 20-30 discharge measurements were taken over the range of observed flows; the mean flow velocity $v$ per vertical was measured at 0.6 of the local depth along 15-20 verticals in a transect. Mean flow depth $d_{m}$ was computed from the cross-sectional flow area $A_{O} / w$ for each measurement, and a relation between $d_{m}$ and discharge $Q$ was established for each site. Given that cross-sectional shapes varied over the reach and that different cross sections were used to facilitate discharge measurements at low and high flows, the hydraulic radius $R$ was determined from $d_{m}$ by assuming a trapezoidal channel cross section with a $45^{\circ}$ bank angle rather than from the ratio $A_{Q}$ /wetted perimeter at each measurement location. Relations of $d_{m}$ and $R$ versus discharge in other studies were either used as reported, estimated based on the text or topographic site maps, or back-calculated if shear stresses $\tau=\rho_{f} \cdot \mathrm{g} \cdot d($ or $R) \cdot S$ were presented. Particle and water densities of 2650 and $1000 \mathrm{~kg} / \mathrm{m}^{3}$ were used for all study streams when computing Shields values because bed particles were either dominated by silica-rich granite/gneiss/ schist lithologies or comprised particle mixes of various densities for which silica density was considered a workable estimate. Viscosity $\nu$ was set to $1.3 \cdot 10^{-6} \mathrm{~m}^{2} / \mathrm{s}$ in the computation of $R e_{p}$. Only a few of the bed load trap study streams had long flow records; hence the bankfull estimate considered both the flow that inundates unvegetated gravel point and/or lateral bars by several $\mathrm{cm}$ and the $Q_{1.5}$ flow from reasonably close gauged basins.

\subsection{Flow Competence, Critical Flow, and Shields Values}

[13] A flow competence curve is the relation between the largest measured bed load particle size $\left.\left(D_{B \max }\right)^{\prime}\right)$ encountered in a bed load sample collected over a sufficiently long time period and discharge $\left(Q^{\prime}\right)$ at the time of sampling, where' denotes individually measured data. In order to predict the critical, i.e., largest, particle sizes mobile at a specified flow, power function regressions were fitted to logtransformed values of $D_{B \max }{ }^{\prime}$ and $Q^{\prime}$ for all study streams:

$$
D_{B \max }=c \cdot Q^{d}
$$

where $c$ is the regression coefficient, and $d$ is the exponent. Most flow competence curves established from bed load trap samples were well defined. Measured flows within a highflow season spanned a 1.2 to 6.3 fold range (mean of 3 ; see also Table 2); the largest particles collected in the bed load traps were in the 90-128 mm class; sampled $D_{B \max }$ sizes spanned a factor of 4-32 depending on encountered high flows, and $r^{2}$ values were within $0.43-0.90$ (see example in Figure 2).

[14] For Helley-Smith samples, the largest $D_{\text {Bmax }}$ particle size was in the 64-90 $\mathrm{mm}$ size class, and the sampled range of $D_{B \max }$ was typically narrower. The HS sampler occasionally collects large particles in relatively low flows, overrepresenting the mobile particle size. At high flows, the short 2 min sampling time reduces the chance of collecting the infrequently moving largest particles [Bunte and Abt, 2005], while the HS opening is too small to accommodate large gravels, both of which cause undersampling of the true $D_{B \max }$. Consequently, flow competence curves derived from HS samples are notably flatter than those from derived from bed load traps (Bunte et al., 2004, 2008, 
BUNTE ET AL.: SHIELDS VALUES IN MOUNTAIN STREAMS

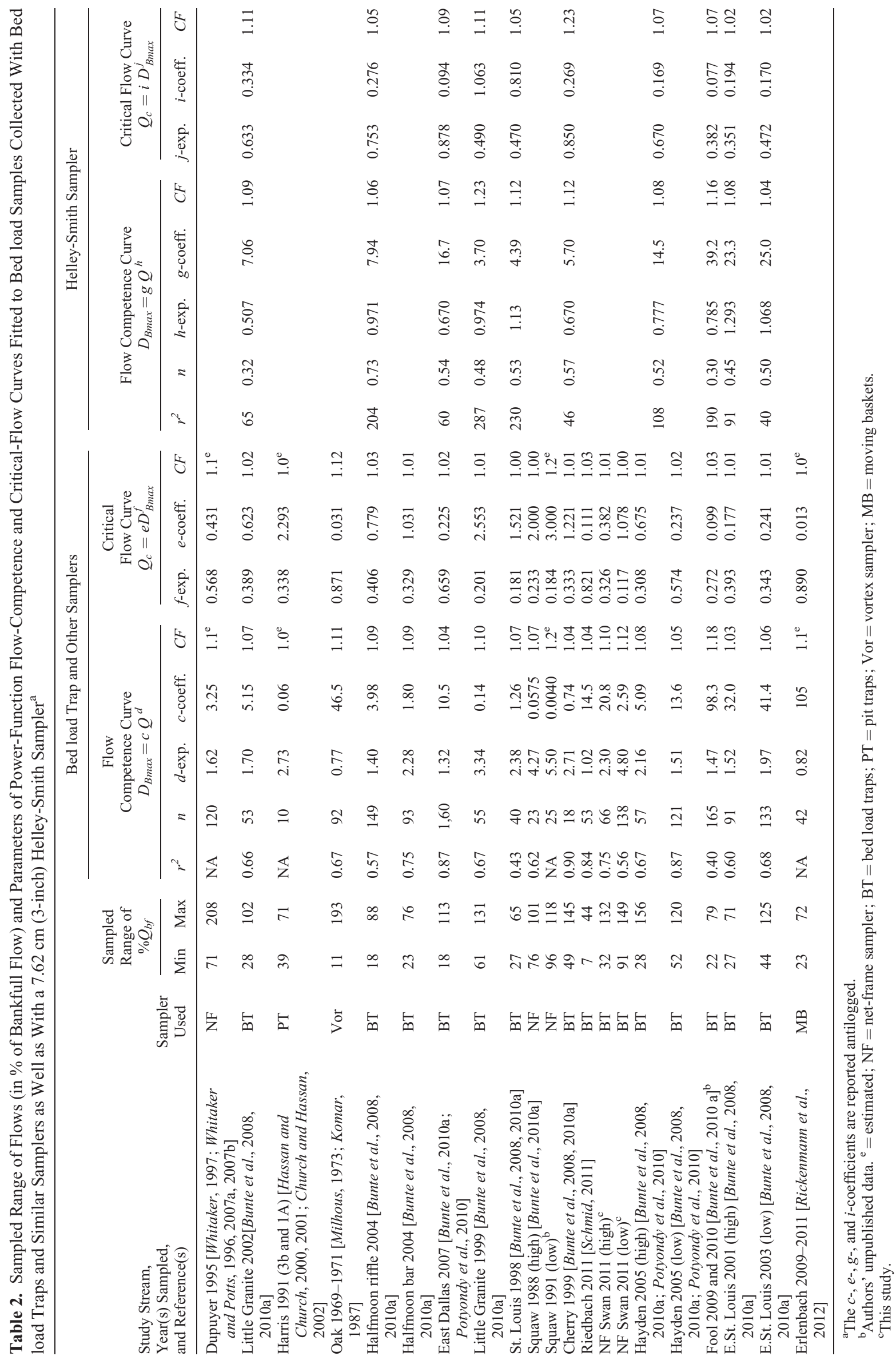


Table 3. Input Parameters for Computation of Various Shields Values

\begin{tabular}{|c|c|c|c|c|}
\hline Shields Value & Input Particle Size & Input Flow & $\begin{array}{l}\text { Required Bed Load Transport } \\
\text { Observations }\end{array}$ & Underlying Assumptions \\
\hline \multicolumn{5}{|c|}{ For Specified Particle Size } \\
\hline & Bed surface $D_{50}$ & $\begin{array}{l}R_{c} \text { at average mobility of } \\
D_{50} \text { size }\end{array}$ & \multirow{5}{*}{$\left.\begin{array}{l}\text { Full field-measured critical } \\
\text { flow curve; Repeated sam- } \\
\text { pling to cover wide range } \\
\text { of } Q_{c} \text { and } D_{B \max } \text { for good } \\
\text { regression fit and to recog- } \\
\text { nize changes in trend }\end{array}\right\}$} & \multirow{5}{*}{$\begin{array}{l}\text { Bed load samples reliably rep- } \\
\text { resent the relation } \\
Q_{c}=f\left(D_{B \max }\right)\end{array}$} \\
\hline$\tau_{c 50 s u b}^{*}, \tau_{c 50 s u b H S}^{*}$ & Bed sub-surface $D_{50 \text { sub }}$ & $\begin{array}{l}R_{c} \text { at average mobility of } \\
D_{50 \text { sub }} \text { size }\end{array}$ & & \\
\hline$\tau_{c 16}^{*}, \tau_{c 16 H S}^{*}$ & Bed surface $D_{16}$ & $\begin{array}{l}R_{c} \text { at average mobility of } \\
D_{16} \text { size }\end{array}$ & & \\
\hline$\tau_{c 84}^{*}, \tau_{c 84 H S}^{*}$ & Bed surface $D_{84}$ & $\begin{array}{l}R_{c} \text { at average mobility of } \\
D_{84} \text { size }\end{array}$ & & \\
\hline$\tau_{c 50, \text { lo.env }}^{*}$ & Bed surface $D_{50}$ & $\begin{array}{l}R_{c} \text { at absolute largest mobile } \\
D_{50} \text { size }\end{array}$ & & \\
\hline \multicolumn{5}{|c|}{ For Specified Flow } \\
\hline$\tau_{c b f}^{*}, \tau_{c b f H S}^{*}$ & $D_{B m a x, b f}$ mobile at $Q_{b f}$ & $\begin{array}{l}R_{b f} \text { at average mobility of } \\
D_{B \max , b f}\end{array}$ & \multirow{2}{*}{$\left.\begin{array}{r}\text { Field-measured flow compe- } \\
\text { tence curve, esp. near } Q_{b f}\end{array}\right\}$} & \multirow{2}{*}{$\begin{array}{l}\text { Bed load samples reliably rep- } \\
\text { resent } D_{B \max , b f}\end{array}$} \\
\hline$\tau_{c b f, u p . e n v}^{*}$ & $D_{B m a x, b f}$ mobile at $Q_{b f}$ & $\begin{array}{l}R_{b f} \text { at absolute largest } \\
D_{B \max , b f} \text { size }\end{array}$ & & \\
\hline \multicolumn{5}{|c|}{ For Specified Flow and Specified Particle Size (=Noncritical Shields Value) } \\
\hline$\tau_{b f 50}^{*}, \tau_{b f 50 H S}^{*}$ & Bed surface $D_{50}$ & $R_{b f}$ & None & $\begin{array}{l}\text { Bed } D_{50} \text { is largest size trans- } \\
\text { ported at } Q_{b f}(=\text { bankfull } \\
\text { mobility })\end{array}$ \\
\hline
\end{tabular}

2010b] (Table 2), and the less steep increase together with a larger data scatter dropped HS $r^{2}$ values to $0.27-0.73$.

[15] At study sites where numerous samples cover a wide range of flows and where gravel supply does not change much over the highflow season, flow competence and critical flow relations in log-log space exhibit straight trends parallel to the upper and lower envelope curves. A few of the data sets from sites not sampled with bed load traps covered a rather narrow range of sampled flows. Here, an overly flat trendline fitted from a least square regression that would mispredict flow competence was avoided by fitting a trendline line through the central data cloud parallel to the upper and lower data envelopes.

\subsubsection{Computation of Critical Particle Sizes and Critical Flows}

[16] The average largest bed load particle sizes $D_{B m a x, b f}$ mobile at bankfull flow $Q_{b f}$ [Bunte et al., 2010a; Bunte, 2012a] were predicted from the flow competence relations (equation (2)) established for each study stream. The general underprediction of the $y$ estimates (here $D_{B m a x, b f}$ ) from $x$ values (here $Q$ ) in fitted power functions was addressed by multiplying the prediction of $D_{B m a x, b f}$ by a bias correction factor $C F=\mathrm{e}\left(2.651 s_{y}{ }^{2}\right)$ [Miller, 1984; Ferguson, $1986,1987]$ where $s_{y}$ is the standard error of the $y$ estimate $\left(D_{B \max , b f}\right)$ :

$$
D_{B \max , b f}=c \cdot Q_{b f}^{d} \cdot C F
$$

[17] Other correction factors are available [e.g., Duan, 1983; Koch and Smillie, 1986; Hirsch et al., 1993], but since sample size was $>30$ and $s_{y}<0.5$ in most cases, CF was selected for computational simplicity.

[18] Critical flows $Q_{c 50}$ required to move the bed surface $D_{50}$ sizes were predicted from power function regressions fitted to $\log$ transformed values of flows $Q_{c}{ }^{\prime}$ at which a particle size $D_{B \max }$ was found mobile against log transformed $D_{B \max }{ }^{\prime}$ sizes $\left(Q_{c}=e \cdot D_{B \max }^{f}\right) ; e$ and $f$ are empirically determined. The critical flow $Q_{c 50}$ for the bedmaterial $D_{50}$ size was computed by solving the critical flow curve for:

$$
Q_{c 50}=e \cdot D_{50}^{f} \cdot C F
$$

[19] The $Q_{c 16}, Q_{c 84}$, and $Q_{c 50 s u b}$ for the bed surface $D_{16}$ and $D_{84}$ and the subsurface $D_{50 \text { sub }}$ sizes were computed accordingly.

\subsubsection{Computation of Shields Values}

[20] Once the bankfull mobile particle size $D_{B \max , b f}$ as well as the $R_{c}$ for mobility of preset particle sizes were known, critical bankfull Shields values $\tau_{c b f}^{*}$ and critical $\tau_{c}^{*}$ values for specified percentile particle sizes were computed by solving equation (1). The notation $\tau_{c 50}^{*}$ refers to mobility of the bed surface $D_{50}$ size, while $\tau_{c 16}^{*}$ and $\tau_{c 84}^{*}$ refer to mobility of the $D_{16}$ and $D_{84}$ sizes, respectively, and $\tau_{c 50 s u b}^{*}$ to the subsurface bed $D_{50}$ size as presented in Table 3. The notation $\tau_{c}^{*}$ refers to unspecified particle sizes. Noncritical bankfull Shields values $\tau_{b f 50}^{*}$ were computed from the bed $D_{50}$ size, $R_{b f}$ and $S_{x}$ (besides $\rho_{s}, \rho_{f}$, and g). This study presents an empirical approach and-similar to Mueller et al. [2005], Pitlick et al. [2008], and Recking [2009] - has computed Shields values without roughness corrections, accepting that Shields values in rough mountain streams back-calculated from field-measured, reachaveraged critical flow parameters and from reliable field observations of particle mobility may be higher than if computed with roughness correction.

[21] The definition of particle mobility affects Shields values, and the range of incipient motion criteria extends from an occasional roll-over of an isolated particle to full participation of a specified particle size in gravel bed load transport [Stelczer, 1981]. In this study, a particle size class was considered mobile at a given flow when it was found to be transported based on the flow competence/critical flow curve (equations (3) and (4)). Consequently, $D_{B \max }$ represents the average largest mobile size of a wide range of $D_{B \max }{ }^{\prime}$ sizes 
collected at the same flow in repeated bed load samples. It might be argued that flow competence and critical flow should rather refer to the absolutely largest particle size found mobile at a specified flow which would be indicated by the upper envelope of the flow competence and the lower envelope of the critical flow data. To investigate the effects of these differences, Shields values $\tau_{c, \text { lo.env }}^{*}$ and $\tau_{c b f, u p . e n v}^{*}$ were computed from particle mobility indicated by the lower envelope of the critical flow curves $Q_{c \text {,lo.env }}$ and the upper envelope curves $D_{B m a x, b f, u p . e n v}$, respectively, using equation (1) (Table 3). Use of different sampler types affects the particle size measured as mobile. To determine the effect of sampler type on calculated Shields values, values of $\tau_{c 50}^{*}$, $\tau_{c 50 s u b}^{*}, \tau_{c 16}^{*}, \tau_{c 84}^{*}, \tau_{b f 50}^{*}$, and $\tau_{c b f}^{*}$ from bed load trap samples were compared to the corresponding Shields values $\tau_{c H S}^{*}$ determined from Helley-Smith samples (Table 3).

[22] Critical flow conditions and critical dimensionless Shields values computed from bed load trap and other representative samplers for the average mobile $D_{B \max }$ particle size are compiled in Table 4. Linear and power functions are used to predict relations of various critical Shields values to stream gradient $S_{x}$ (Table 5) because both regression types are presented in the literature, and both yield similar predictions for the central data range. Power functions are preferable on physical grounds. Neither of the functions should be extrapolated beyond the range of $S_{x}\{0.01-0.105\}$, especially not the linear functions which would provide unreasonably low predictions of $\tau_{c}^{*}$ for small gradients.

[23] We suggest that our results are applicable to mountain streams in temperate climates in the indicated range of gradients, under conditions of frequently occurring highflows (20$\left.150 \% Q_{b f}\right)$ and sediment supply conditions associated with those events. Established torrents with high sediment supply may have a different relation of $\tau_{c b f}^{*}$ versus $S_{x}$; Catastrophic debris torrents as well as streams with virtually no sediment supply are not included in the study. Note also that bankfull flow is morphologically not well represented in such channels.

\section{Results}

\subsection{Critical Shields Values for the Bed $D_{50}$ and Other Particle Sizes}

\subsection{1. $\tau_{c 50}^{*}$ Values From Steep Streams in the Shields Diagram}

[24] Particle Reynolds numbers $R e_{p}$ reach 6000-50000 for the mountain study streams. Hence critical Shields values $\tau_{c 50}^{*}$ from this study plot on the right side of the Shields diagram as shown in Figure 3, far beyond $R e_{p}=500$ where Shields [1936] ended his experiments and assumed constancy for $\tau_{c 50}^{*}$. The $\tau_{c 50}^{*}$ values back-computed for the study streams cover a 6.5 -fold range from 0.033 to 0.22 , a range spanned by extrapolating to $R e_{p} 50000$ both the steep increase of the Shields curve observed within $R e_{p} 30-70$ and the minimum Shields value just above 0.03 . The wide range shows that a single value of $\tau_{c 50}^{*}$ cannot describe incipient motion of the bed $D_{50}$ size in mountain streams and that $R e_{p}$ is not a good predictor of $\tau_{c 50}^{*}$.

\subsection{2. $\tau_{c}^{*}$ Values Increase With Stream Gradient and are Stratified by Relative Depth and Relative Roughness}

[25] $\tau_{c 50}^{*}$ values from the study presented here have a strong positive relation with $S_{x}$ (Figure 4) that is well described by a linear and a by power function (Table 5). Compared to other empirical relations for mountain streams [Rosgen, 1994; Mueller et al., 2005; Pitlick et al., 2008; Schneider et al., submitted manuscript, 2013] and to those modeled [Recking, 2009; Ferguson, 2012], the relation $\tau_{c 50}^{*}=f\left(S_{x}\right)$ from this study ranges within the center of those depicted in Figure 1 when $S_{x}$ is smaller than 0.05, but is higher than the reported relations for $S_{x}>0.05$.

[26] The alignment of $\tau_{c 50}^{*}$ values with the Montgomery and Buffington [1997] stream type is loose (Figure 4), suggesting that each stream type may require a range of $\tau_{c 50}^{*}$ values for particle motion, but the alignment provides first estimates of $\tau_{c 50}^{*}$ in the field. For mixed pool-riffle/planebed streams and plane-bed streams with forced pool-riffle sequences, respectively, average critical Shields values of 0.055 and 0.065 are a good starting point. For plane-beds with low steps and low gradient step-pool streams $\left(S_{x}<0.05\right)$ respectively, average values of 0.108 and 0.092 are good estimates, and an average value of 0.21 may be suitable for steep step-pool streams $\left(S_{x}\right.$ close to 0.1$)$. However, the association of $\tau_{c 50}^{*}$ values with stream type offers no improvement in prediction because the stream type classification is mainly based on $S_{x}$.

[27] The increase of $\tau_{c}^{*}$ values with stream gradient might be ascribed to several factors. The increase is numerically explainable because $S_{x}$ (numerator in equation (1)) spans a wider (10-fold) range in the steep study streams than $R_{c}$ and particle sizes $D_{50}, D_{84}$, etc., that each span a 2 to 4 -fold range, hence $S_{x}$ exerts the largest control over computed $\tau_{c}^{*}$ values. By contrast, Wiberg and Smith [1987], Mueller et al. [2005], Lamb et al. [2008], Recking [2009], and Ferguson [2012] attributed the increase of $\tau_{c}^{*}$ with stream gradient to physical causes, including near-bed hydraulic conditions, grain force balance, and total flow resistance. Other factors that are commonly associated with steep streams are increasing relative protrusion or relative roughness $\left(D_{84} / d\right)$, bed material sorting, a decrease in relative flow depth $\left(d / D_{50}\right)$, and an increase in the structural stability of the bed (e.g., by imbrication, steps, particle wedging, and stone structures [Church et al., 1998]), all of which could also act on their own to increase $\tau_{c}^{*}$ without the additional effects of $S_{x}$. Teasing out the effects of poor bed mobility and $S_{x}$ on $\tau_{c}^{*}$ would be desirable and a subject for further research.

[28] Similar to results shown by Mueller et al. [2005], scatter in the relation of $\tau_{c 50}^{*}$ versus $S_{x}$ for the study streams is narrowed when the data are stratified by relative bankfull flow depth $\left(d_{b f} / D_{50}\right)$ as well as by relative roughness $\left(D_{84} /\right.$ $\left.d_{b f}\right)$ (Figure 5). Hence, stratification improves the prediction of $\tau_{c 50}^{*}$ from $S_{x}$, as shown in Table 5. The ratio $d_{b f} / D_{50}$ best stratifies the relation of $\tau_{c 50}^{*}$ versus $S_{x}$, whereas $D_{84} / d_{b f}$ explains the Erlenbach outlier that is not explained by $d_{b f} /$ $D_{50}$. Stratifications by $d_{b f} / D_{50}$ and $D_{84} / d_{b f}$ are well developed for moderately steep channels with $S_{x}$ in the range of $0.02-0.04$, whereas the stratification lines converge as $S_{x}$ approaches $0.01 \mathrm{~m} / \mathrm{m}$. In general, $\tau_{c 50}^{*}$ increases as streams become shallower and rougher (Figure 5). This is expected because shallow relative flow depths and rough beds in steep channels are associated with poor bed mobility. However, for stream beds of equal steepness, deeper $\left(d_{b f} / D_{50}\right)$ and smoother $\left(D_{84} / d_{b f}\right)$ channels yield higher values for $\tau_{c 50}^{*}$ than shallower and rougher streams, the opposite of 
Table 4. Critical Flow Depth $d_{c}$, Critical Hydraulic Radius $R_{c}$, and Critical Dimensionless Shields Values for the Bed Surface $D_{50}$, $D_{50 \text { sub }}, D_{16}$, and $D_{84}$ Particle Sizes as Well as for Bankfull Flow at the Study Streams

\begin{tabular}{|c|c|c|c|c|c|c|c|c|c|c|c|c|c|c|c|c|c|}
\hline $\begin{array}{l}\text { Stream and Ye } \\
\text { Sampled }\end{array}$ & $\begin{array}{r}d_{c 50} \\
(\mathrm{~m})\end{array}$ & $\begin{array}{r}R_{c 50} \\
(\mathrm{~m})\end{array}$ & $\tau_{c 50}^{*}$ & $\begin{array}{l}d_{c 50 s u b} \\
(\mathrm{~m})\end{array}$ & $\begin{array}{l}R_{c 50 s u b} \\
\quad(\mathrm{~m})\end{array}$ & $\tau_{c 50 s u b}^{*}$ & $\begin{array}{l}d_{c 16} \\
(\mathrm{~m})\end{array}$ & $\begin{array}{r}R_{c 16} \\
(\mathrm{~m})\end{array}$ & $\tau_{c 16}^{*}$ & $\begin{array}{l}d_{c 84} \\
(\mathrm{~m})\end{array}$ & $\begin{array}{r}R_{c 84} \\
(\mathrm{~m})\end{array}$ & $\tau_{c 84}^{*}$ & $\begin{array}{l}d_{c b f} \\
(\mathrm{~m})\end{array}$ & $\begin{array}{r}R_{c b f} \\
(\mathrm{~m})\end{array}$ & $\tau_{c b f}^{*}$ & $\begin{array}{l}R_{b f} \\
(\mathrm{~m})\end{array}$ & $\tau_{b f, 5}^{*}$ \\
\hline & & & 057 & & & & & & & & & 01 & & & & & 0.06 \\
\hline ite 2002 & & & 33 & & & & & & & & & & & & 66 & & 03 \\
\hline 1 ( $3 \mathrm{~B}$ and 1 & 8 & & & & & & & & & & & & & & & & 0.11 \\
\hline moon (riffle) 2004 & .53 & 7 & 82 & & & & & & 12 & & & 41 & 71 & 0.61 & 92 & & 0.10 \\
\hline & & & & & & & & & & & & & & & & & \\
\hline & 0.23 & 6 & & & & & & & & & & & & & & & 50 \\
\hline as & 29 & 7 & 8 & & & & & 0 . & 42 & & & .028 & 0 & 0.28 & 47 & 28 & 0.050 \\
\hline & 29 & & & & & & & & & & & & & & & & \\
\hline & 0.40 & & & & & & & & & & & & & & & & 06 \\
\hline t. Lo & & & & & & & & & 0.141 & & & 21 & & & 99 & & 0.04 \\
\hline$C_{n}$ & 30 & .29 & .085 & & & & & 0.26 & & & & & & 0.31 & & & 0.09 \\
\hline & & & & & & & & & & & & & & & & & 0.09 \\
\hline & 0.48 & 0.44 & & & & & & 0.36 & 0.841 & & & & 0.42 & & & & 0.114 \\
\hline 2011 & 0.41 & .38 & 119 & & & & 0.22 & 0.22 & 0.523 & 57 & 0.52 & 0.055 & 0.41 & 0.39 & 46 & 39 & 0.121 \\
\hline & 0.23 & 0.21 & & & & & & & & & & & & 0.22 & & & 0.101 \\
\hline $\mathrm{IF}$ & & 0.24 & & & & & & & & & & & 0.23 & 0.22 & & & 0.07 \\
\hline Hay & 0.29 & 0.27 & 99 & & & 2 & 0.23 & 0.22 & 0.363 & & 0.31 & 43 & 0.26 & 0.24 & 50 & 24 & 0.08 \\
\hline Hayden 2005 & 0.30 & & & & & & & & 0.312 & & & & 0.26 & 0.24 & & & 0.08 \\
\hline E. S & 0.53 & 0.41 & & & & & 0.36 & 0.30 & 1.136 & & 0.46 & & 0.44 & 0.35 & & 0.35 & 0.18 \\
\hline E. St. Louis 2003 (low) & 0.55 & 0.42 & 0.218 & & & & 0.39 & & & & 0.46 & & 0.44 & 0.35 & 0.776 & 0.35 & 0.18 \\
\hline Fool 2009-2010 & 0.20 & 0.15 & 0.076 & & & & 0.16 & & & & 0.16 & & 0.20 & 0.15 & & & 0.07 \\
\hline Erlenbach 2009-2011 & 0.22 & 0.19 & 0.212 & 0.17 & 0.15 & 0.399 & 0.12 & 0.11 & 0.902 & 0.31 & 0.27 & 0.086 & 0.31 & 0.29 & 0.122 & 0.29 & 0.31 \\
\hline
\end{tabular}

${ }^{\mathrm{a}}$ See Table 1 for $d_{b f}$ and $D_{50}$.

Table 5. Regressions Fitted to Relations Between Various Shields Values (Based on Bed load Trap Field Data) and Stream Gradient

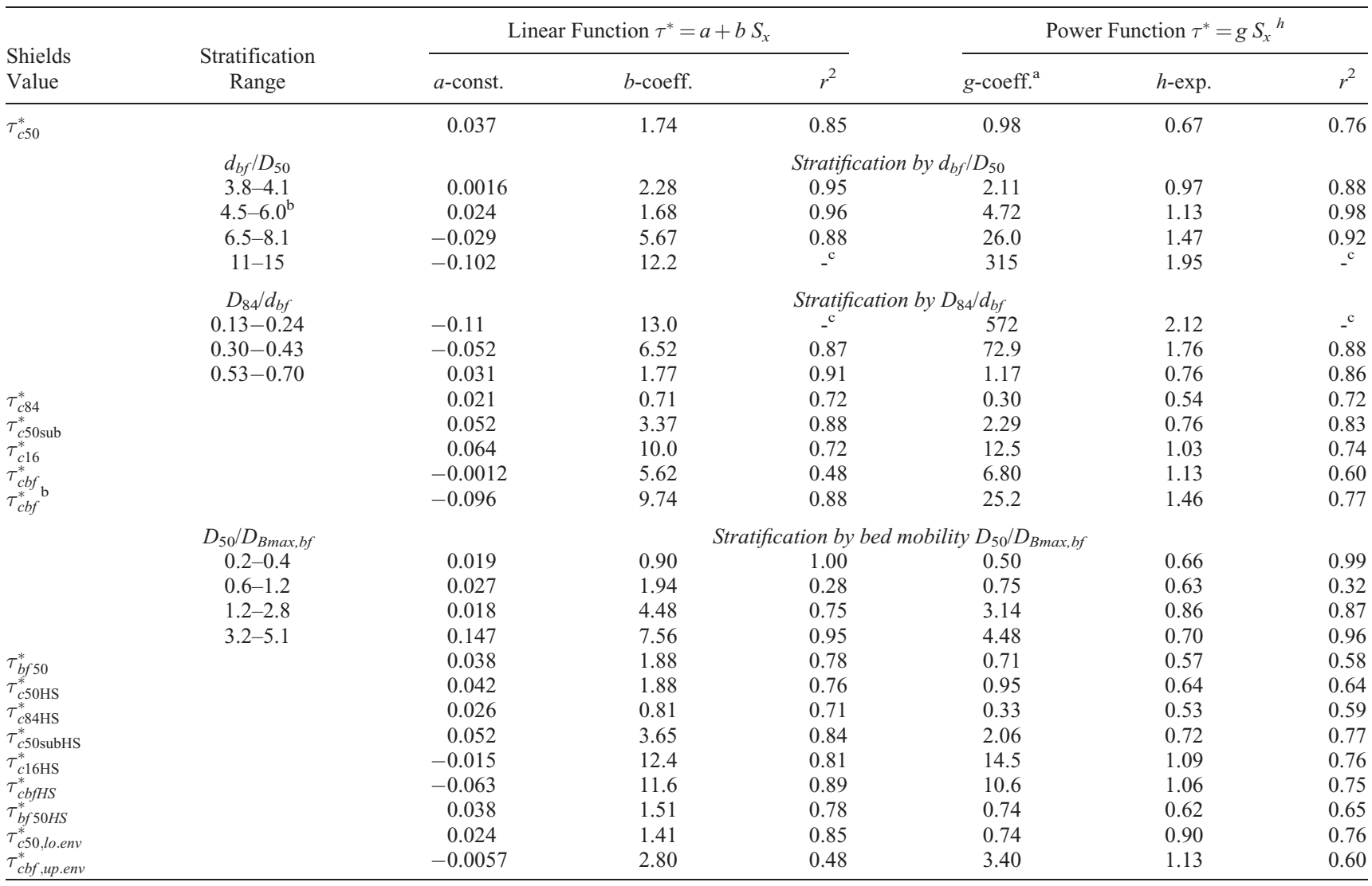

${ }^{a}$ The power-function $g$-coefficients are reported anti-logged. The $a$-constant in linear fits indicates $\tau^{*}$ values for zero-gradient channels, while the $b$ coefficient (actually $b-a$ ) indicates $\tau^{*}$ for a $100 \%$ slope $\left(45^{\circ}\right.$ angle). In the power fit, the $g$-coefficient indicates $\tau^{*}$ at a $100 \%$ slope, while the $h$-exponent indicates how steeply the function $\tau^{*}=f\left(S_{x}\right)$ curves upward.

${ }^{\mathrm{b}}$ Erlenbach excluded from regression.

${ }^{\mathrm{c}}$ Handfitted. 


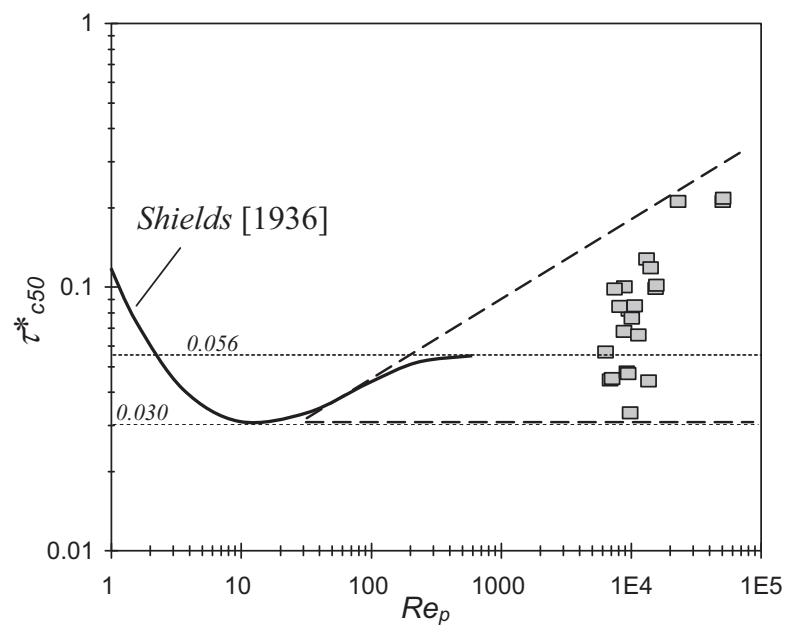

Figure 3. Critical Shields values $\tau_{c 50}^{*}$ computed for the mountain study streams plot to the right side of the Shields diagram, covering a range between the steepest upward trend of the Shields curve within $R e_{p}$ of $30-70$ and the lowest Shields values (thick dashed lines).

the general trend, which might suggest that other physical effects may overwhelm the effects of relative depth and roughness. However, being part of the Shields equation (equation (1)), the ratio $d_{b f} / D_{50}$ (and the related term $D_{84} /$ $d_{b f}$ ) can also numerically control the Shields value. Besides the two ratios above, other channel parameters that correlate with $S_{x}$ and that might be influencing the relation $\tau_{c 50}^{*}$ versus $S_{x}$ were found to show little effect. Bed material sorting which typically increases with $S_{x}$ and may be expressed as the ratio $D_{84} / D_{50}$ as used by Ferguson [2012] or the Inman [1952] sorting coefficient $\left(\left|\phi_{84}-\phi_{16}\right| / 2\right)$ does not stratify the $\tau_{c 50}^{*}$ versus $S_{x}$ relation in this study. Similarly, the parameters $Q_{b f}, \%$ subsurface fines $<8 \mathrm{~mm}$, basin

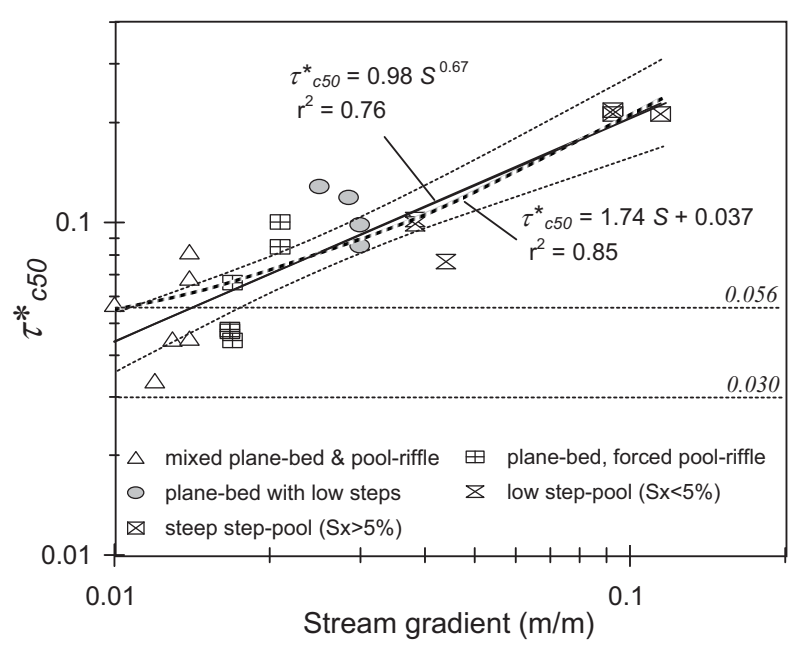

Figure 4. Relations of $\tau_{c 50}^{*}$ with stream gradient and the Montgomery-Buffington [1997] stream types. The solid line shows the fitted power function, and thin dashed lines show $95 \%$ confidence intervals. The ribbon line shows the fitted linear regression.
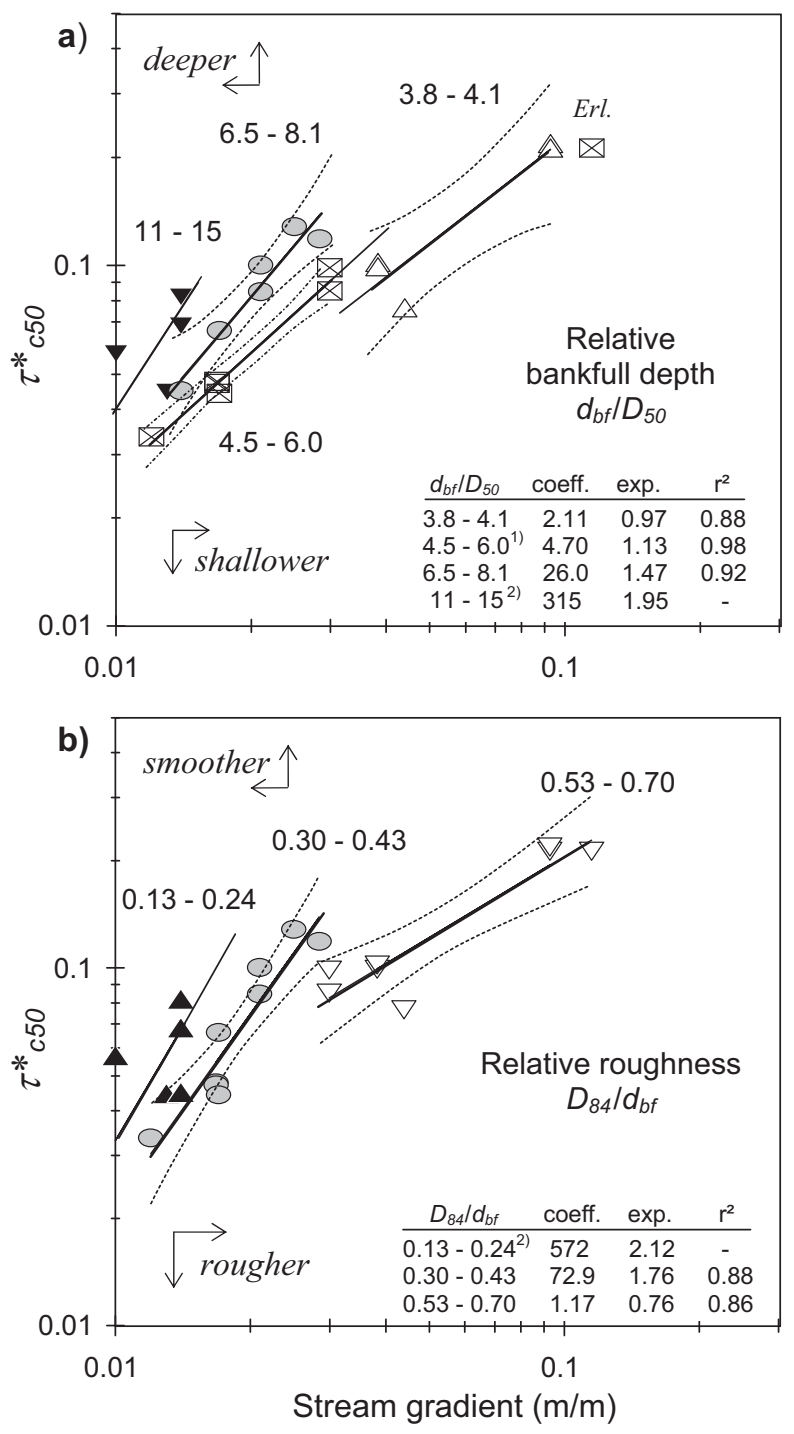

Figure 5. Stratification of the relationship $\tau_{c 50}^{*}$ versus $S_{x}$ by (a) relative bankfull depth $\left(d_{b f} / D_{50}\right)$ and (b) relative bankfull roughness $\left(D_{84} / d_{b f}\right)$. The outlier in the group $4.5-$ $6.0 d_{b f} / D_{50}$ is the Erlenbach, a steep mountain torrent with high sediment supply [Turowski et al., 2009, 2011] that was not included in the regression. Thin dashed lines show $95 \%$ confidence intervals. Inset tables provide parameters for stratifying power functions. ${ }^{(1)}$ Excl. Erlenbach; ${ }^{(2)}$ handfitted in accordance with other relations. See Table 5 for linear regressions.

area $A$, bankfull stream width $w_{b f}$, and the bed $D_{16}$ size that decrease with $S_{x}$ had weak negative relation with $\tau_{c 50}^{*}$ but also do not improve prediction of the $\tau_{c 50}^{*}$ versus $S_{x}$ relation. Nevertheless, those weak relations suggest that $\tau_{c}^{*}$ is somewhat affected by characteristics of stream steeps in ways other than $S_{x}$ exerting a numerical artifact.

[29] Bed mobility or stability is a parameter that should affect Shields values, associating higher critical Shields values with less mobile streams. Bed mobility can be quantified as the ratio $\tau_{b f 50}^{*} / \tau_{c 50}^{*}$ [e.g., Buffington, 2012] which is essentially the depth ratio $d_{b f} / d_{c 50}$. Alternatively, bed 
stability may be quantified by the grain size ratio $D_{50}$ / $D_{B \max , b f}$ where $D_{B \max , b f}$ is the largest particle size mobile at bankfull flow. The mobility and the stability parameters are inversely related to each other $\left(r^{2}=0.59\right.$ for the study streams). The grain-size ratio is preferred over the depth ratio in this study because the parameter $D_{B m a x}, b f$ is used to assess stream stability, (e.g., Kaufmann et al. [2008, 2009] who predict $D_{B \max , b f}$ from the bed $D_{50}$ size and an analytical expression of the Shields curve) as well as for stream restoration. $D_{50} / D_{B m a x, b f} \cong 1$ defines bankfull stability for particles $\geq D_{50}$ or bankfull mobility for particles $\leq D_{50}$, whereas ratios $>1$ indicate stable beds and ratios $<1$ indicate unstable beds. In contrast to relative depth $d_{b f} / D_{50}$ and the relative roughness $D_{84} / d_{b f}$ (Figure 5), neither the depth ratio for bed mobility nor the grain-size ratio expression for bed stability stratifies the relation of $\tau_{c 50}^{*}$ versus $S$. High bed stability or low mobility is only weakly associated with higher critical Shields values $\tau_{c 50}^{*}$ as shown in Figure 6. The poorly developed relations of $\tau_{c 50}^{*}$ with $D_{50} / D_{B m a x, b f}$ and $d_{b f} / D_{50}$ suggest that bed stability/mobility has a minor influence on $\tau_{c 50}^{*}$ compared to the major (and perhaps largely numerical) effect exerted by stream gradient. Figure 6 shows that each stream type experiences a wide range of bed stability (perhaps due to differences in sediment supply), hence the relation of bed stability to $\tau_{c 50}^{*}$ and to stream type remains unclear [Buffington, 2012]. Similarly, the diagonal trends of the ratios $d_{b f} / D_{50}$ and $D_{84} / d_{b f}$ in the plots of $\tau_{c 50}^{*}$ versus $S_{x}$ (Figure 5) suggest that relative depth and relative roughness are related to stream type in very general terms only and that any stream type (or stream gradient class) may experience a range of different $d_{b f} / D_{50}$ and $D_{84} / d_{b f}$ conditions at incipient motion of the $D_{50}$ particle size. More field data on measured incipient motion and further development in the morphological description of stream types regarding bed mobility/stability and sediment supply might help to bring clarification of this issue.

\subsubsection{Critical Shields Values for Different Particle} Sizes

[30] Depending on the application, entrainment might need to be predicted for particle sizes other than the bed $D_{50}$ size, necessitating size-specific Shields values. $\tau_{c 84}^{*}$ values are required to predict mobility of the bed surface $D_{84}$ or when analyzing streambed erosion thresholds; $\tau_{c 16}^{*}$ values back-computed from the bed $D_{16}$ size may be required for determining flows that flush fine gravel from a coarse bed. Similar to $\tau_{c 50}^{*}$, critical Shields values $\tau_{c 50 s u b}^{*}$, $\tau_{c 16}^{*}$, and $\tau_{c 84}^{*}$ in the study streams also increase with stream gradient (Figure 7 and Table 5), but the relations $\tau_{c}^{*}=$ $f\left(S_{x}\right)$ differ among particle sizes. $\tau_{c 84}^{*}$ values are on average half as large as $\tau_{c 50}^{*}$, while $\tau_{c 50 s u b}^{*}$ values for the subsurface bed material $D_{50}$ size are nearly twice as large as $\tau_{c 50}^{*} ; \tau_{c 16}^{*}$ values exceed $\tau_{c 50}^{*}$ on average by a factor of 3.5. The relations $\tau_{c}^{*}=f\left(S_{x}\right)$ double in steepness from $\tau_{c 84}^{*}$ to $\tau_{c 16}^{*}$ (Figure 7). Progressively higher values for $\tau_{c 84}^{*}, \tau_{c 50}^{*}$ and $\tau_{c 16}^{*}$ are also shown by Recking [2009]. The linear regressions for $\tau_{c 50}^{*}$ and $\tau_{c 84}^{*}$ versus $S_{x}$ fitted in the current study are generally similar to Recking's, albeit somewhat steeper and higher. The $\tau_{c 50}^{*}$ and $\tau_{c 84}^{*}$ values based on bed load trap samples exceed Recking's by about $20 \%$, whereas the relation $\tau_{c 16}^{*}$ versus $S_{x}$ is up to 3 times higher and considerably steeper (Figure 8) (see Discussion for further exploration of the differences between the two studies).
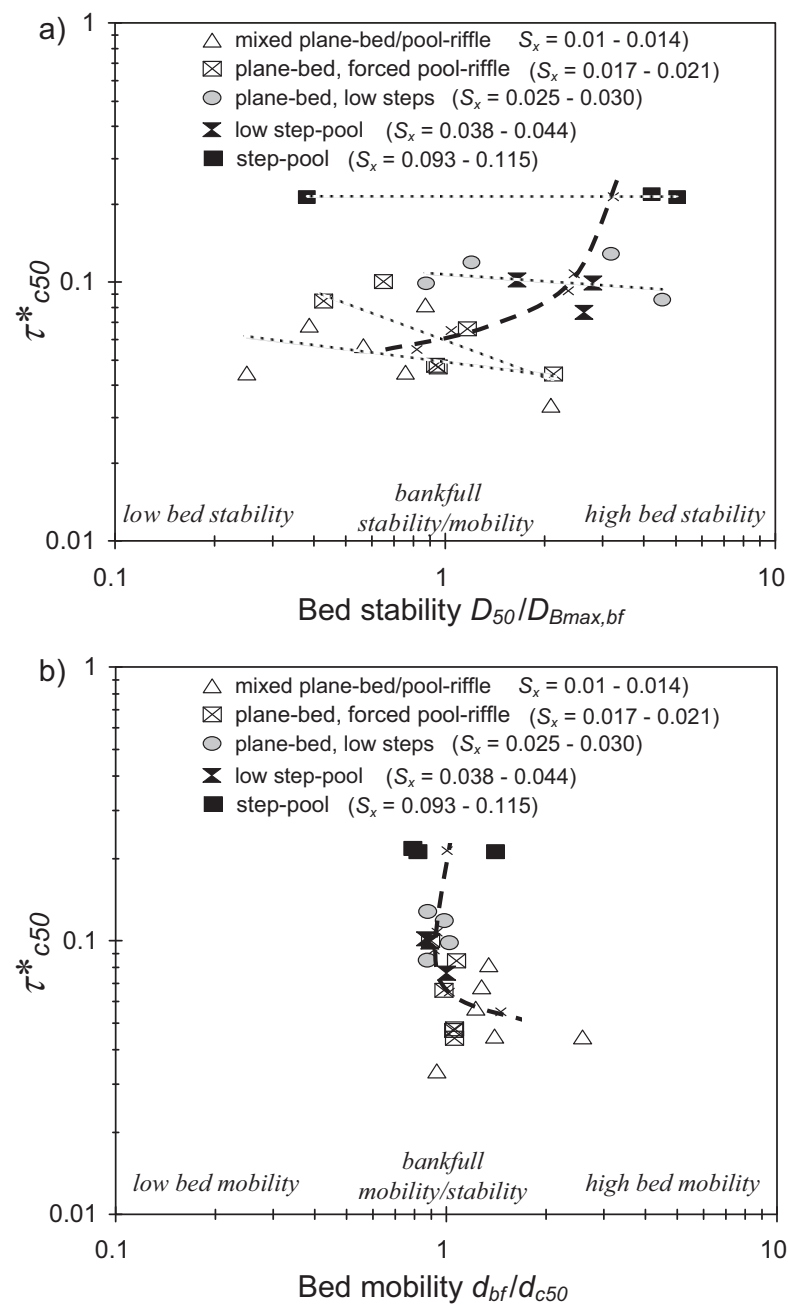

Figure 6. Relations of $\tau_{c 50}^{*}$ with bed stability/mobility expressed by (a) $D_{50} / D_{B m a x, b f}$ and (b) $d_{b f} / d_{c 50}$. Dotted lines in Figure $6 a$ depict fitted trendlines for individual stream types; plane-bed streams with low steps and low-gradient step-pool streams were grouped. Thick dashed lines indicate the trend fitted by eye. The $S_{x}$ ranges indicated for individual stream types refer to those encountered in this study.

\subsection{Critical Bankfull Shields Values}

\subsubsection{Scattered Relation of $\tau_{c b f}^{*}$ With Stream} Gradient

[31] Critical Shields values $\tau_{c b f}^{*}$ backcalculated from the average largest bed load particle sizes collected at bankfull flows $\left(D_{B \max , b f}\right)$ (equation (3)) span a 32-fold range for the study streams, five times wider than the range of $\tau_{c 50}^{*}$ values. $\tau_{c h f}^{*}$ values increase steeply with $S_{x}$ as portrayed in Figure 9. The increase of $\tau_{c b f}^{*}$ with $S_{x}$, that is steeper than for $\tau_{c}^{*}=f\left(S_{x}\right)$ of any individual particle size, is caused by the extreme differences in bankfull flow competence among mountain streams.

[32] A low and very low bankfull flow competence with values of $\tau_{c b f}^{*}>0.1$ is typical where $S_{x}$ is larger than 0.02 or $0.03 \mathrm{~m} / \mathrm{m}$ and sediment supply is low-hence effects of structural bed stability set in. Given that bankfull flow in 


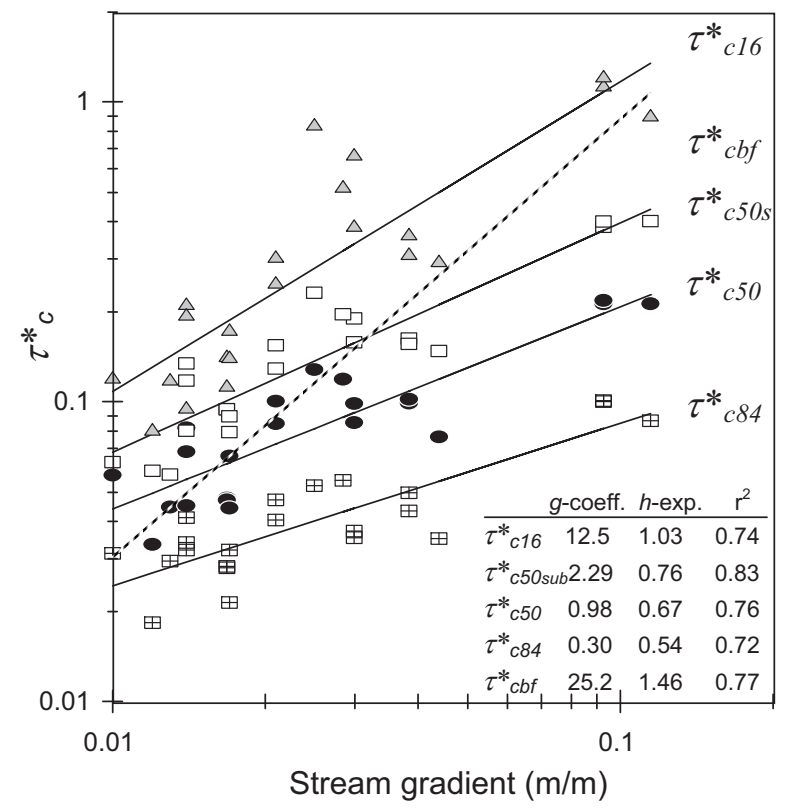

Figure 7. Relations of $\tau_{c}^{*}$ values for the bed material $D_{84}$, $D_{50}, D_{50 \text { sub }}$, and $D_{16}$ sizes with stream gradient $\left(S_{x}\right)$. Fitted power functions are shown in solid lines. The relation of $\tau_{c b f}^{*}$ with $S_{x}$ (diagonal ribbon line, from Figure 9) is shown for comparison. The inset table provides the regression parameters, the Erlenbach is excluded for $\tau_{c b f}^{*}$. See Table 5 for linear regression functions.

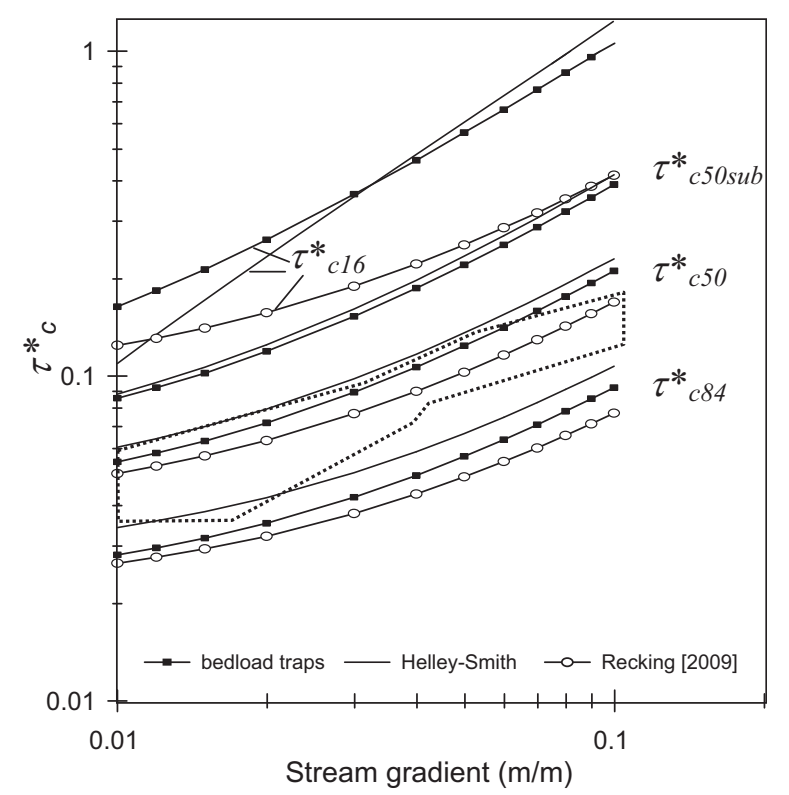

Figure 8. Linear regressions of $\tau_{c}^{*}=f\left(S_{x}\right)$ for the bed material $D_{84}, D_{50}, D_{50 \text { sub }}$, and $D_{16}$ sizes fitted to bed load trap and Helley-Smith samples (Table 5) compared with $\tau_{r}^{*}$ relations modeled by Recking [2009] for the $D_{84}, D_{50}, D_{16}$ particle sizes. Empirical HS-based relations from Figure 1 are contained within the encircled area but exclude the flume data, the noncritical $\tau_{b f, 50}^{*}$ and $\tau_{b f, 50 s u b}^{*}$ [Mueller et al., 2005; Pitlick et al., 2008], and the mainly bed load trap based $\tau_{r 50}^{*}$ data from J. M. Schneider et al. (submitted manuscript, 2013). those plane-bed and step-pool streams moves only particles that were $20-50 \%$ of the bed surface $D_{50}$ size, computed $\tau_{c b f}^{*}$ values are 2 to 5 times higher than $\tau_{c 50}^{*}$, and $\tau_{c b f}^{*}$ approaches the $\tau_{c 16}^{*}$ values (see Figure 7). About half of the study streams are incapable of moving their bed $D_{50}$ sizes at bankfull flow, and those streams may be classified as semi-alluvial [Meshkova et al., 2012; Bunte, 2012b]. The bed is rough and has a high degree of structural stability from particle interlock and wedging, from low (about 1 particle high) steps and high immobile boulder steps. The channels are typically incised and gravel bars are lacking, but most of those streams have occasional hydraulically forced patches of mobile gravel [Yager et al., 2007, 2012; Nelson et al., 2009, 2010]. By contrast, in some of the lower-gradient mountain streams where $S_{x}$ is $0.01-0.02$, as well as in the steep Erlenbach torrent with its high sediment supply, its highly erodible bed sediment and propensity to summer flash floods [Molnar et al., 2010; Turowski et al., 2009], bankfull flow transports particles up to twice the bed $D_{50}$ size. Consequently, $\tau_{c b f}^{*}$ values are about half those for $\tau_{c 50}^{*}$, approaching the $\tau_{c 84}^{*}$ values computed for low $S_{x}$. Presence of active gravel bars, often within a channel incised into a largely inactive floodplain, is a common feature for this group of streams.

\subsubsection{Stratification of $\tau_{c b f}^{*}=f\left(S_{x}\right)$ by Bed Stability}

[33] With data scatter over an order of magnitude, the relation $\tau_{c b f}^{*}=f\left(S_{x}\right)$ is not well suited to provide guidance for selection of suitable values for $\tau_{c b f}^{*}$ (Table 5), and narrowing the scatter via stratification is desirable. Because

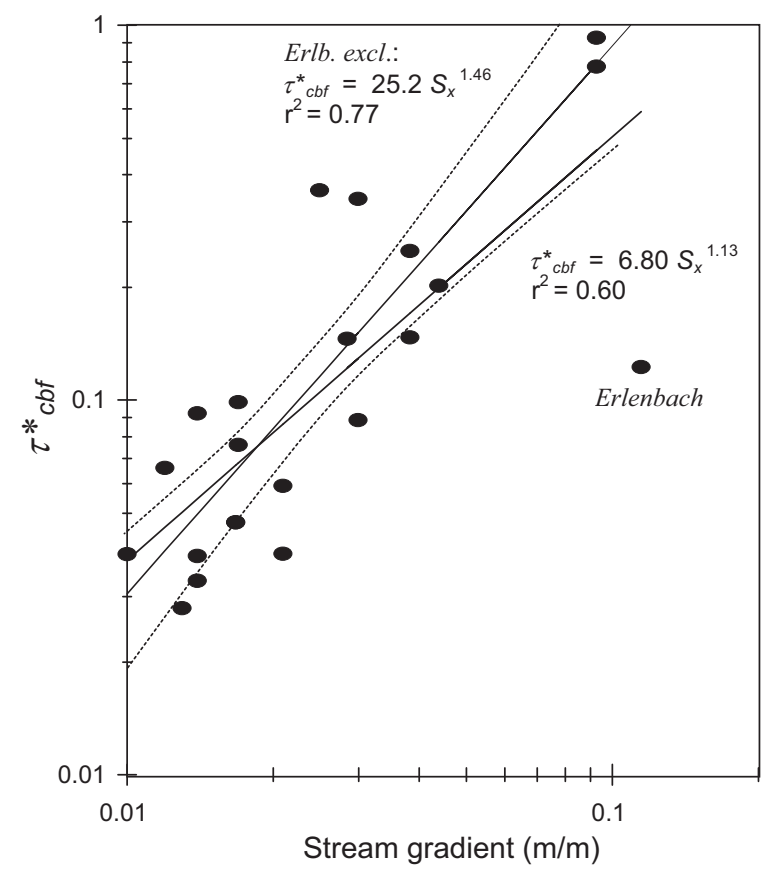

Figure 9. Critical Shields values $\tau_{c b f}^{*}$ computed from the largest particle sizes mobile at bankfull flow versus stream gradient $S_{x}$. The low $\tau_{c b f}^{*}$ value for the Erlenbach torrent reduces the correlation coefficient. Excluding the Erlenbach, the best-fit regression (thin line) is more suited for steep streams with low sediment supply. Thin dashed lines show $95 \%$ confidence intervals. See Table 5 for linear regression functions. 


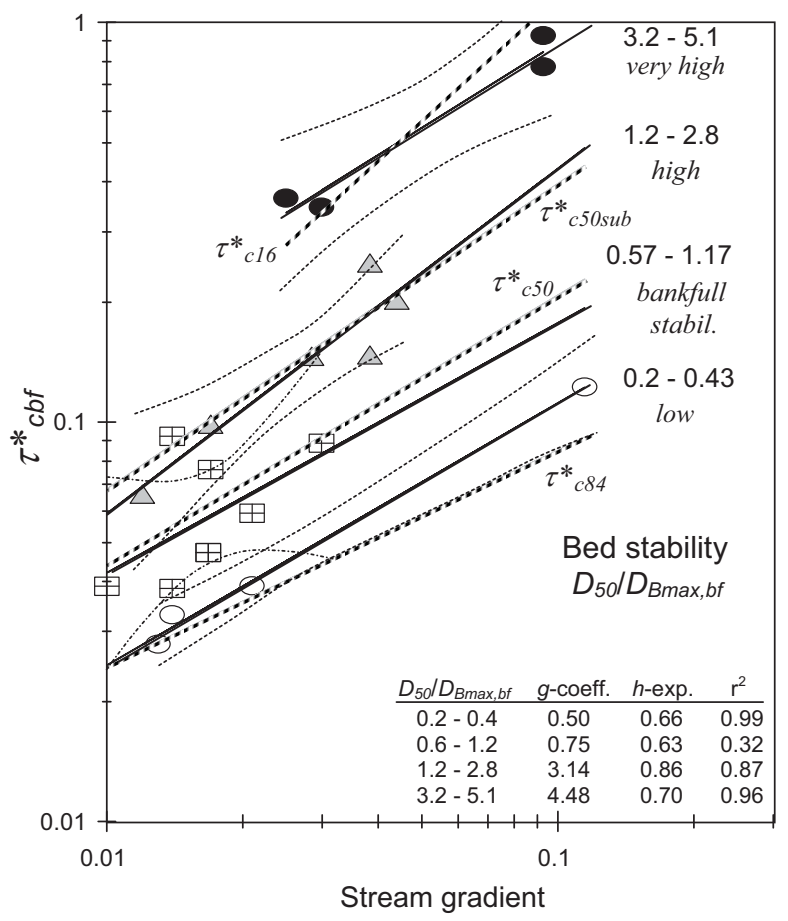

Figure 10. Stratifications of the relations $\tau_{c b f}^{*}=f\left(S_{x}\right)$ by relative bed mobility (solid lines). Streams for which $D_{50} /$ $D_{b \max , b f}$ is within 0.6-1.2 may be considered bankfull mobile streams. Inset tables provide parameters for stratifying power regressions, and thin dashed lines show $95 \%$ confidence intervals. See Table 5 for linear regressions. Ribbon lines show relations $\tau_{c}^{*}=f\left(S_{x}\right)$ established for various particle size percentiles in Figure 7.

the measured bankfull mobile particle size $D_{B \max }, b f$ from which $\tau_{c b f}^{*}$ is computed is part of the bed stability term $\left(D_{50} / D_{B \max , b f}\right)$, it is not surprising that scatter in the relation of $\tau_{c b f}^{*}=f\left(S_{x}\right)$ (Figure 9) can be explained by $D_{50} / D_{B \max , b f}$ as shown in Figure 10. For a specified gradient, the less stable streams (lower values of $D_{50} / D_{B \max , b f}$ ) have lower $\tau_{c b f}^{*}$ values. Low bed stability also explains the rather low $\tau_{c b f}^{*}$ value in Figure 9 for the highly erodible sediment step-pool Erlenbach torrent [Turowski et al., 2009, 2011; Molnar et al., 2010]. Compared to the wide scatter in the relation of $\tau_{c b f}^{*}=f\left(S_{x}\right)$, stratification by bed stability improved the predictions (Figure 10 and Table 5). We are aware of the circularity here: $D_{B \max , b f}$ is used to compute $\tau_{c b f}^{*}$, hence the ratio $\left.D_{50} / D_{B m a x}, b f\right)$ stratifies the relation $\tau_{c b f}^{*}=f\left(S_{x}\right)$. However, the aim is to provide an estimate for the unknown $\tau_{c b f}^{*}$ with which to compute $D_{B m a x, b f}$ in unmeasured streams. The fitted stratifying relations can be practically employed to improve the prediction of $\tau_{c b f}^{*}$ from stream gradient if estimates of relative bed mobility or stability can be gleaned from a visual assessment of morphological and granulometric channel features. Especially after performing a 400-particle pebble count, an operator has some idea of which particle sizes are mobile or are stuck in the bed and whether particles much larger or smaller than the bed $D_{50}$ size might move at bankfull flow. Hence, bed stability expressed by the grain size ratio $D_{50} / D_{B \max , b f}$ is easier to assess in the field than the depth ratio expression for bed mobility $d_{b f} / d_{c 50}$ which also did not stratify $\tau_{c b f}^{*}=f\left(S_{x}\right)$. Indicators of low bankfull bed stability in steep coarsebedded streams include abundance of active gravel bars with particle sizes finer than the thalweg bed material, obvious near-stream sediment sources, as well as a high percent of surface and subsurface sand and pea gravel, and relatively many large particles that lie fully exposed on top of the bed. Signs of low sediment supply are low presence of fines on and in the bed, sediment retention by nearby dams, possibly presence of algae and moss cover, particles that are stuck deeply in the gravel/cobble bed, and indicators of structural bed stability (e.g., particle wedging, imbrication, stone structures). If bed stability can be roughly categorized as very high, high, bankfull stability, and low, critical bankfull Shield values $\tau_{c b f}^{*}$ can be estimated accordingly. Adopting a finer morphological stream classification that considers bars and sediment supply as well as bed material texture and structure would be helpful to illuminate bed mobility/stability (e.g., torrent and lowstep plane-bed as subtypes of step-pool; alternate bars and plane-bed without bars but meandering thalweg as subtypes of pool-riffle).

[34] Interestingly, the relations $\tau_{c b f}^{*}=f\left(S_{x}\right)$ stratified by bed stability align with the relations established for mobility of specific percentile particle sizes presented in Figure 10: $\tau_{c b f}^{*}$ values for very high, high, and low bed stability approximate those for $\tau_{c 16}^{*}, \tau_{c 50 s u b}^{*}$, and $\tau_{c 84}^{*}$, respectively. In bankfull mobile/stable streams, $\tau_{c b f}^{*}$ values are similar to $\tau_{c 50}^{*}$ values. These results suggest that streams with high bed stability transport their subsurface $D_{50 \text { sub }}$ size at bankfull flow; highly mobile streams transport their bed surface $D_{84}$, and very stable streams transport their $D_{16}$ sizes at bankfull flow. Hence, $\tau_{c 16}^{*}, \tau_{c 50 s u b}^{*}$, and $\tau_{c 84}^{*}$ provide estimates of $\tau_{c b f}^{*}$ for very high, high, and low bed stability, respectively, while $\tau_{c 50}^{*}$ is an estimate of $\tau_{c b f}^{*}$ for bankfull mobile/stable streams. The illustrated correspondence between bankfull mobility/stability and mobility of specific bed material percentile sizes would benefit from more field data and may serve as a rule of thumb only. Nevertheless, estimating bankfull $\tau_{c b f}^{*}$ values from a $\tau_{c}^{*}$ value in reference to estimated bed stability is an improvement over the sweeping use of $\tau_{c 50}^{*}$ or the noncritical value $\tau_{b 5,50}^{*}$ as an estimate of bankfull $\tau_{c b f}^{*}$ without regard to bed stability.

\section{Discussion}

\subsection{Uncertainty in Computed Shields Values}

[35] Random errors in the input parameters to the Shields equation (equation (1)) within and among studies contribute to uncertainty of $\tau_{c}^{*}$ values as well as to scatter in relations of $\tau_{c}^{*}$ with $S_{x}$ and other variables. Yet with a sufficiently large number of $\tau_{c}^{*}$ values, random errors should on average cancel out and not alter those relations. Bias, by contrast, systematically increases or decreases computed Shields values and changes the relations of $\tau_{c}^{*}$ with $S_{x}$ and other variables. Both error types are addressed below.

\subsubsection{Effects of Unbiased Errors in $\rho_{s}, R, S_{x} D_{50}$, and} $D_{B \max }$ on $\tau_{c}^{*}$

[36] Errors in $\rho_{s}$ typically result from using the particle density for quartz $\left(2650 \mathrm{~kg} / \mathrm{m}^{3}\right)$ instead of the actual density for a specific rock type. Not accounting for a channel 
bed made up entirely of sandstone particles with $\rho_{s}=2300$ $\mathrm{kg} / \mathrm{m}^{3}$ would overpredict $\tau_{c}^{*}$ by $27 \%$, while not accounting for a basalt $\rho_{s}$ of $3000 \mathrm{~kg} / \mathrm{m}^{3}$ would underpredict $\tau_{c}^{*}$ by $21 \%$. Hence a user may adjust results presented here for particular rock densities. However, streambeds commonly comprise a mix of different rock densities. In aggregate, they may approach quartz density, or necessitate a more accurate but rather involved analysis that apportions $\rho_{s}$ to the percentage frequency of different lithologies and to the different composition of lithologies in each size class, an unlikely routine.

[37] Stream gradients can be determined accurately when survey equipment is used, but hand levels can introduce errors as large as 30\% [Isaak et al., 1999; Halwas and Church, 2002]. Errors in field-determined bankfull flow can also be large [Roper et al., 2008; Buffington et al., 2009], but the resulting errors in $d_{b f}$ (and $R_{b f}$ ) are only about half as large because $d=k Q^{l}$, where $l$ is typically within $0.3-0.6$. Letting $Q_{b f}$ in the study streams vary by \pm 20 and $\pm 40 \%$ changed $R_{b f}$ on average by \pm 9 and $\pm 20 \%$, respectively. Without doing a formal propagation of error calculation, the combined random errors in $\rho_{s}, R$, and $S_{x}$ are estimated to be approximately $15 \%$ for the bed load trap study streams.

[38] In coarse-bedded streams, the bed $D_{50}$ as well as $D_{84}$ sizes may differ by a factor of two among studies that use different field methods, stemming mainly from differences in sampling location within the reach, particle selection and measurement, and sample size [Bunte et al., 2009]. Errors in the bed $D_{16}$ may be twice as high because the $D_{16}$ size typically constitutes the fine tail of a skewed frequency distribution that is associated with higher variability [Rice and Church, 1996; Bunte and Abt, 2001a, $2001 \mathrm{~b}$ ]. Subsurface $D_{50 \text { sub }}$ sizes reported among studies likely differ more than surface $D_{50}$ sizes because differences in sample volume and sampled depth further contribute to variability [Bunte and Abt, 2001a]. Detailed bed material sampling efforts in the bed load trap study streams kept errors in the $D_{50}$ and $D_{84}$ bed material sizes at an estimated $5 \%$, and at $10-20 \%$ for the $D_{16}$ and $D_{50 \text { sub }}$ sizes.

[39] The error potential for the $D_{B \max }$ size from misfitted flow competence/critical flow curves is high unless a large number of bed load samples have been collected. Individual days of a snowmelt highflow season typically exhibit well-defined relations of $D_{B \max }$ versus $Q$ and of $Q_{c}$ versus $D_{B m a x}$, but changes in sediment supply cause the relations to differ over consecutive days and within the highflow season (e.g., Figure 2), resulting in daily and seasonal hysteresis [e.g., Mao, 2012; Swingle et al., 2012]. Combining all daily relations of $D_{B \max }$ versus $Q$ over a highflow season produces a scatter of $1-2 \phi$ units (a factor of 2-4) between the smallest and the largest instantaneous $D_{B \max }$ collected for a given flow [Bunte et al., 2008, 2012a] (e.g., Figure 2). Given the high natural variability of the largest transported bed load particle sizes, taking only a few isolated samples over a highflow season yields a scattered flow competence relation, while concentrating field sampling on a single day produces a well-defined relation of $D_{B \max }$ versus $Q$, but records only one of the many daily relations that exist over the highflow season. Intensive sampling that covers the highflow season is the only way to avoid this problem. In those study streams where 6-10 daily bed load measure- ments covered most days of the highflow season and where the flow-competence and critical-flow relations were segregated to accommodate periods of different sediment supply (e.g., rising and falling limbs of flow), errors in $Q_{c}$ or $D_{B \max }$ from (mis-) fitted flow-competence and critical-flow relations are guessed to be 5-10\%. With lower sampling intensity and less highflow coverage, errors in fitted flowcompetence and critical-flow curves may increase to 20$50 \%$, and errors are typically largest early in the highflow season when $D_{B \max }$ sizes tend to be most variable.

[40] The combined errors from several input parameters in the current study are estimated to introduce 5-50\% errors to computed $\tau_{c}^{*}$ values. In studies where sampling methods produce inappropriate estimates of bed material size or where too few bed load samples are available to accurately define the flow-competence and critical-flow relations, errors in $\tau_{c}^{*}$ values may amount to a factor of 2 .

\subsubsection{Effects of Biased Errors in $D_{B \max }$ Sizes on $\tau_{c}^{*}$}

[41] Biased errors in the $D_{B \max }$ size or in critical flow $Q_{c}$ can stem from bed load samplers that produce biased samples. Flow competence and critical flow curves determined from bed load traps and a 7.6 by $7.6 \mathrm{~cm}$ Helley-Smith (HS) sampler at the same site differ considerably: the HS placed directly onto the stream bed collects larger gravel particles than bed load traps at low flows but smaller gravel particles at high flows [Bunte et al., 2004, 2008, 2010b, 2010c, 2012]. Consequently, flow-competence curves from the two samplers intersect (mostly within 60 and $80 \%$ of bankfull flow and mostly within $D_{B \max }$ sizes of 10 to $30 \mathrm{~mm}$ ). HS flow-competence curves in this study have exponents of $0.5-1.3$ and are less than half as steep as those from bed load traps deployed at the same sites (exponents of 1.3-3.5) (Table 2). Similarly, HS critical-flow curves have exponents of $0.35-0.88$ (mean of 0.59 ) that are on average 1.6 times steeper than those from bed load traps (0.18-0.66, mean of 0.37 ). Those sampler-induced differences are reflected in back-computed Shields values. At study sites where both samplers were employed, the relations of $\tau_{c}^{*}=$ $f\left(S_{x}\right)$ computed for the $D_{50 \text { sub }}, D_{50}$, and $D_{84}$ sizes are similarly steep for both samplers, but $\tau_{c H S}^{*}$ values are on average higher by 6,9 , and $15 \%$, respectively (Figure 8 ). The relations $\tau_{c 16}^{*}=f\left(S_{x}\right)$ intersect for the two samplers, and $\tau_{c 16 H S}^{*}$ values are smaller than the bed load trap $\tau_{c 16}^{*}$ values for $S_{x}<0.03$. The HS sampling bias against large gravel and cobbles overpredicts critical flow mobilizing coarse particles (and hence $R_{c}$ ) which, in turn, overpredicts Shields values for coarse particles. By analogy, the HS propensity for sampling overly coarse particles at low flows and on lower gradient streams explains the average lower $\tau_{c 16}^{*}$ values for the HS. Similar to bed load trap results for $\tau_{c b f}^{*}$ (see Figure 7), $\tau_{c b f H S}^{*}$ values resemble $\tau_{16}^{*}$ in steep streams $\left(S_{x} \cong 0.1\right)$. In gentler gradient streams with $S_{x}=0.01, \tau_{c b f H S}^{*}$ values approach $\tau_{c 50 s u b}^{*}$ whereas the bed load trap $\tau_{c b f}^{*}$ approaches $\tau_{c 84}^{*}$. Hence, HS samples suggest bankfull mobility of the bed $D_{50 \text { sub }}$ size rather than $D_{84}$ particles in lower gradient streams and underpredict bed mobility. Many of the field data used by Recking [2009] for his relations $\tau_{c}^{*}=f\left(S_{x}\right)$ are derived from HS samplers and tracer studies. However, Recking's relations (Figure 8)which are lower than those from bed load traps-differ more from the HS-derived $\tau_{c}^{*}$ relations in this study than from the bed load trap relations of $\tau_{c}^{*}=f\left(S_{x}\right)$. 

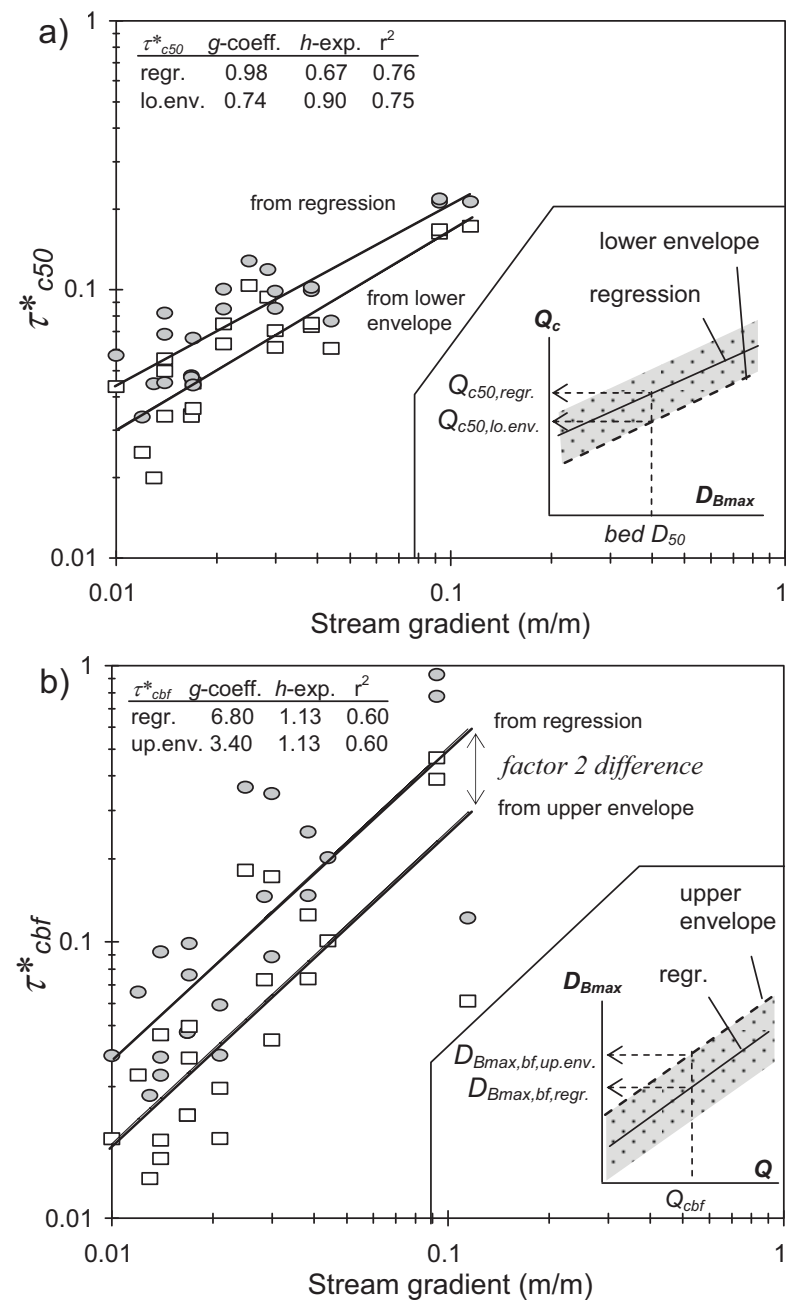

Figure 11. (a) Values of $\tau_{c 50}^{*}=f\left(S_{x}\right)$ obtained from the regression function (gray circles) and the lower envelope (open squares) of the critical flow curve and fitted power regressions $\tau_{c 50}^{*}=f\left(S_{x}\right)$ (Table 5). Inset figure shows regression (solid line) and the lower envelope $Q_{c 50, \text { lo.env }}$ (dashed line) of the critical flow curve. (b) Values $\tau_{c b f}^{*}=$ $f\left(S_{x}\right)$ obtained from the regression function (gray circles) and the upper envelope curve (open squares) of the flow competence curve and fitted power regressions $\tau_{c b f}^{*}=f\left(S_{x}\right)$. Inset figure shows flow competence regression function (solid line) and the upper envelope (dashed line). Inset tables in (a) and (b) provide power function regression parameters.

Computational differences other than use of a particular bed load sampler obviously contribute to the differences in the $\tau_{c}^{*}$ relations between the studies.

[42] A relatively large bias is introduced to $\tau_{c}^{*}$ values if computations are based on either the absolutely largest particle size observed to be mobile at a specific flow or on the average largest size. The decision to use either one may depend on the study aim: averaging over a number of $D_{B \max }$ observations may be useful for regime characterizations, whereas the absolutely largest mobile particle size may be important for design questions that require a safety margin. The absolutely largest mobile particle size is indi- cated by the upper envelope of the flow competence data. For large flow competence data sets, that envelope is typically well defined rather than constituting an individual outlier data point. By extension, where particle mobility is expressed in terms of critical flow, mobility may refer to the average critical flow (regression function) or the lowest critical flow at which a specific particle size was observed to be mobile (lower envelop curve). When sufficient field data cover a wide flow range, the envelopes have the same slopes as fitted regression functions but are shifted, on average, upward by a factor of 2 (1.6-2.3 in the study streams) for flow competence curves, and downward by a factor of nearly two for critical flow curves.

[43] The effects of using the absolutely largest versus the average largest mobile particle size on $\tau_{c}^{*}$ values can be estimated by halving the $e$-coefficients of the fitted power function critical flow curves (equation (4)) (Table 2). Halving the $e$-coefficients halves $Q_{c}$ for a given $D_{B \max }$. The resulting reduction of $d_{c}$ (and hence $R_{c}$ ) is about half as much because $d$ increases with $Q$ with the power of $0.3-0.6$ (see above). Not unexpectedly then, $\tau_{\text {clo.env }}^{*}$ values computed from the absolutely largest mobile particle sizes in the study streams were on average $25 \%$ lower than $\tau_{c}^{*}$ computed from the average largest mobile particle size as presented in Figure 11a. The 25\% reduction was observed for all particle sizes $\left(\tau_{c 16}^{*}, \tau_{c 50}^{*}\right.$, and $\left.\tau_{c 84}^{*}\right)$ and could explain the 25 and 38\% lower $\tau_{c 50}^{*}$ and $\tau_{c 84}^{*}$ relations shown by Recking [2009] (Figure 8), suggesting that his $\tau_{c}^{*}$ values might be derived from absolutely largest rather than average largest mobile particle sizes. Reasons for the up to 3 -fold difference in the $\tau_{c 16}^{*}$ relations between the two studies for steep gradients $\left(S_{x}>5 \%\right)$, however, remain unclear. Using the absolutely largest versus the average largest particle sizes has a larger effect on $\tau_{c b f}^{*}$ values determined from the flow competence equation (equation (3)). Doubling the $c$-coefficient doubles the $D_{B m a x, b f}$ size which causes $\tau_{c b f, u p \cdot e n v}^{*}$ values to be halved (Figure 11b).

[44] Finally, biases may occur if the flow competence/critical flow approach is applied to natural streams as opposed to flumes where bed morphology and flow hydraulics are less spatially varied. In many steep streams it may be more likely that a collected $D_{B \max }$ particle was not entrained from the bed in front of the sampler but originated from a more mobile gravel patch upstream, and once entrained, continued its downstream path, perhaps aided by secondary currents. Hence $\tau_{c}^{*}$ values derived from the flow competence/critical flow approach in natural streams may be lower for a specified particle size, $R$ and $S_{x}$ than in flume experiments conducted on a bed material with similar grain size distribution. By contrast, surface particles in beds of natural streams with low sediment supply may arrange to maximize bed stability (e.g., imbrication, wedging, stone structures) which may make those beds less entrainable than less structured flume beds with similar bed particle sizes.

\subsection{Hiding and Exposure}

\subsubsection{Difference in Critical Shields Values Between Particle Sizes}

[45] Our study shows a systematic increase of $\tau_{c}^{*}$ values for the $D_{84}$ to the $D_{50}$ and the $D_{16}$ sizes (Figure 7). Wiberg and Smith [1987] attributed higher $\tau_{c}^{*}$ values for smaller particles to the effects of small particles hiding between 
larger ones and being therefore less well entrainable than from uniformly sized fine beds. Similarly, lower $\tau_{c}^{*}$ values for larger particles were attributed to exposure above neighboring smaller particles which enhances entrainability of large particles in mixed sized beds compared to entrainment from uniformly sized coarse beds. However, higher $\tau_{c}^{*}$ values for smaller particles do not necessarily indicate that smaller particles require deeper flows for mobilization than coarser ones. One might also consider that the difference between small and large particle sizes spans a wider range than critical flow depths and influences $\tau_{c}^{*}$ (equation (1)) more than $R_{c}$. Values of $\tau_{c 16}^{*}$ in the study streams are on average 3.5 times larger than those of $\tau_{c 50}^{*}$, whereas critical flow depths for the bed $D_{16}$ size $\left(R_{c 16}\right)$ are on average $73 \%$ of those of $R_{c 50}$, and the $D_{50}$ sizes are on average 4.7 times larger than the $D_{16}$ sizes. Hence, $\tau_{c 16}^{*}$ exceeding $\tau_{c 50}^{*}$ is more attributable to dissimilarity between the two grain sizes rather than to changes in $R_{c}$. Similarly, $\tau_{c 84}^{*}$ values are on average 0.48 times those of $\tau_{c 50}^{*}$, while the $R_{c 84}$ values are 1.12 times those of $R_{c 50}$, and $D_{50}$ values are 0.41 times those of $D_{84}$; again differences in grain-size (where $D_{84}$ is typically $>2 D_{50}$ ) contribute more to $\tau_{c 50}^{*}$ exceeding $\tau_{c 84}^{*}$ than differences in critical flow. That higher $\tau_{c}^{*}$ values for smaller particles are attributable to hiding, and lower $\tau_{c}^{*}$ values for larger particles to exposure is also not supported by our field observations of bedmaterial surfaces during pebble counts at low flows and by visual observations of bed load dynamics at moderate high flows. Typically, we do not encounter many small surface gravels (e.g., 4-16 $\mathrm{mm})$ that are lodged deeply in interstices between large particles (coarse gravel and small cobble) inaccessible to flow. Small gravels mobile during moderate high flows most likely originated their downstream journey on a localized, recently flooded, relatively mobile deposit of small gravels somewhere upstream. Once within the main channel bed, small gravel particles scurry around immobile larger gravels and cobbles, traveling over low lying (large) particles that are flanked by protruding (large) particles. Secondary currents aid transport of small particles by sweeping them to smoother transport paths along the banks, while eddies sweep fines gravels in and out of cobble wake deposits. In pebble counts we typically find relatively few large particles that are fully exposed on top of the bed ready for transport. Instead, many coarse gravels and small cobbles are either stuck deeply in the bed with only a small portion of the particle exposed to flow or are locked in bed structures (imbrication, stone structures, wedged between neighboring particles). For coarse material, entrainability appears to be controlled less by the degree to which the particle is exposed above its neighbors than by the extent to which the particle reaches below the bed surface.

\subsubsection{Hiding Function Exponents}

[46] Hiding functions in the form $\tau_{c i}^{*} / \tau_{c 50}^{*}=\left(D_{i} / D_{50}\right)^{\beta}$ [Parker et al., 1982; Andrews, 1983] are sometimes used to assess mobility of particle sizes other than the $D_{50}$. The value estimated for $\tau_{c i}^{*}$ depends on the $\beta$-exponent for which a range from about -0.5 to -1.1 is commonly reported, but no relation exists from which to predict $\beta$ (e.g., Schneider et al., submitted manuscript, 2013). The back-calculated values of $\tau_{c 16}^{*}, \tau_{c 50}^{*}$, and $\tau_{c 84}^{*}$ in this study were used to estimate hiding function exponents $\beta$ for all study streams. The range of $D_{i} / D_{50}$ extends from $0.1-0.3$ at the low end to 2-3 at the high end, and none of the hiding functions show a change in trend. Values of $\beta$ were found to range from -0.51 to -0.92 . This study determined empirically that $\beta$ is related to the exponents of the critical flow and flow competence curves. Hiding function exponents $\beta$ closer to -1 are associated with flatter critical flow relations (lower exponents $f$ ) and steeper flow competence curves (higher exponents $d$ ). For $\beta$ from -0.92 to -0.66 , the best fit logarithmic functions between $\beta$ and the exponents of the critical flow $(d)$ and flow competence $(f)$ curves are $\beta=-0.72-0.28 \log (d)$ and $\beta=-0.68+0.27 \log (f)$; $r^{2}$ values are 0.76 and 0.75 , respectively, and $n=17$. The relations fall apart for $\beta\{-0.66$ to -0.51$\}$. Power functions can be fitted over the entire range of $\beta$ when using the term $\beta+1$ (adding 1 seems to better preserve the relation between individual $\beta$ than multiplication by -1$). \beta$ is related to the exponents $d$ of the flow competence curves by $\beta+1=0.36 d^{-0.78}$ and by $\beta+1=0.44 f^{0.75}$ to the exponents of the critical flow curves; $r^{2}=0.64, n=22$, and $s_{y}=0.137$ for both regressions. The relations of $\beta$ with the steepness of the critical flow/flow competence curves are not unexpected. For a given stream, the hiding function may be simplified to $\left(R_{c i} / D_{i}\right) /\left(R_{c 50} / D_{50}\right)=\left(D_{i} / D_{50}\right)^{\beta}$, assuming constancy of $\rho_{f}, \rho_{s}$, and $S_{x}$. If $D_{i}$ and $D_{50}$ are eliminated from the left hand side term, the resulting equation represents a dimensionless curve of critical flow depth $R_{c i} / R_{c 50}=\left(D_{i} / D_{50}\right)^{\varphi}$ which has a positive exponent $\varphi$ and is related to the critical flow and flow competence curves. Although determinable, the relations of $\beta$ or $\beta+1$ with the $f$ and $d$ exponents are not practical to predict the hiding function exponent $\beta$ given the large field effort required to obtain a well-defined critical flow or flow competence curve. $\beta+1$ was also found to increase with $d_{b f} / D_{50}$, but not well correlated, and appears to be nonmonotonically related to $D_{84}$ and $D_{84} / D_{50}$. Those moderate correlations make prediction of $\beta$ a problem for unsampled streams.

\subsection{Specific Shields Values Are Required for Specific Purposes}

\subsection{1. $\tau_{b f 50}^{*}$ No Substitute for $\tau_{c 50}^{*}$}

[47] In the absence of field-measured particle mobility, a study might estimate critical Shields values for the bed surface $D_{50}$ size $\left(\tau_{c 50}^{*}\right)$ from noncritical bankfull flow and the bed $D_{50}$ size $\left(\tau_{b f 50}^{*}\right)$ [e.g., Buffington et al., 2004, 2006; Buffington, 2012]. In the mountain study streams, $\tau_{b f 50}^{*}$ values increase with stream gradient as shown by Buffington [2012], although with larger data scatter than $\tau_{c 50}^{*}$ (Table 5). Noncritical dimensionless bankfull shear stress values $\left(\tau_{b f 50}^{*}\right)$ provide accurate estimates of $\tau_{c 50}^{*}$ in streams that can just transport their bed $D_{50}$ particles at bankfull flow where $\tau_{b f 50}^{*}=\tau_{c 50}^{*}=$ bankfull stability. The study presented here found the ratios $\tau_{b f 50}^{*} / \tau_{c 50}^{*}$ to decrease systematically with bed mobility or stability (Figure 12), reaching 1.6 for the least stable streams and decreasing to around 0.9 for the most stable ones, whereas Parker et al. [2007] suggested a general ratio of 1.6 for $\tau_{b f 50}^{*} / \tau_{c 50}^{*}$. With a ratio of $1.6, \tau_{b f 50}^{*}$ overpredicts $\tau_{c 50}^{*}$ by approximately $60 \%$ in highly mobile streams; in very stable ones, $\tau_{b f 50}^{*}$ underpredicts $\tau_{c 50}^{*}$ by $10 \%$.

\subsection{2. $\tau_{c b f}^{*}$ Required to Predict the Bankfull Mobile Particle Size}

[48] Only critical bankfull Shields values $\tau_{c b f}^{*}$ (which are based on the largest particle size measured to be mobile at 


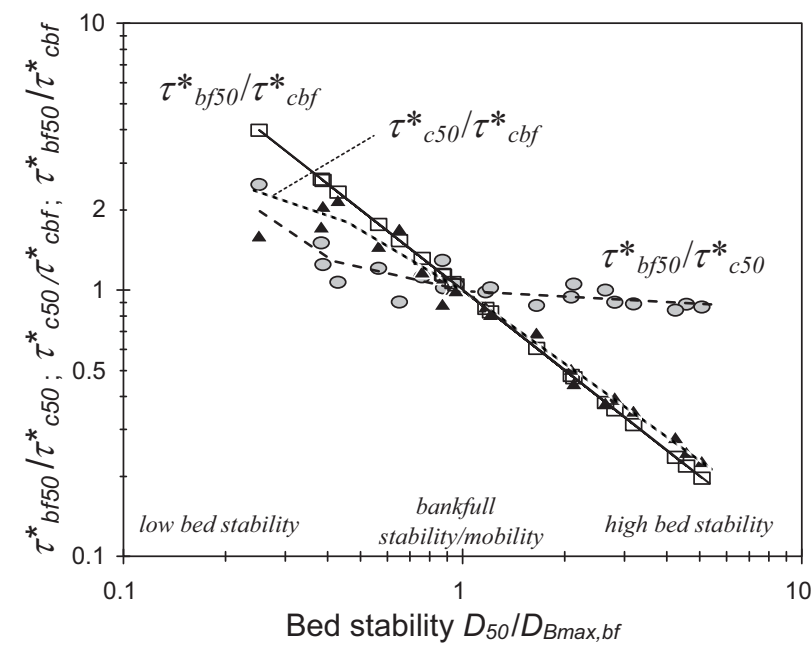

Figure 12. Ratios of various Shields values plotted versus relative bed stability $D_{50} / D_{B \max , b f}$ for the study streams: noncritical bankfull $\tau_{b f 50}^{*}$ to critical $\tau_{c 50}^{*}$, critical $\tau_{c 50}^{*}$ to critical bankfull $\tau_{c b f}^{*}$; and noncritical bankfull $\tau_{b f 50}^{*}$ to critical bankfull $\tau_{c b f}^{*}$.

bankfull flow) can predict the largest bankfull mobile particle size $\left(D_{B \max , b f}\right)$. As shown for the study streams, $\tau_{c b f}^{*}$ differed from $\tau_{c}^{*}$ for other particle sizes (Figure 7). Therefore, no single value $\left(\tau_{c 16}^{*}, \tau_{c 50}^{*}, \tau_{c 50 s u b}^{*}\right.$, or $\left.\tau_{c 84}^{*}\right)$ can be used as a general predictor for $D_{B m a x}, b f$, except for bankfull mobile/ stable streams where $\tau_{c b f}^{*}=\tau_{c 50}^{*}$. Otherwise, values of $\tau_{c 50}^{*}$ differ widely from $\tau_{c b f}^{*}$ depending on bed stability $\left(D_{50} /\right.$ $\left.D_{B \max , b f}\right)$. The negative relation of the ratio $\tau_{c 50}^{*} / \tau_{c b f}^{*}$ with bed stability presented in Figure 12 shows that $\tau_{c b f}^{*}$ is less than half the value of $\tau_{c 50}^{*}$ on poorly stable beds (low values of $\left.D_{50} / D_{B \max , b f}\right)$. On highly stable beds, $\tau_{c b f}^{*}$ is more than three times the value of $\tau_{c 50}^{*}$. If $\tau_{c 50}^{*}$ was used instead of $\tau_{c b f}^{*}$ to estimate $D_{B \max , b f}, \tau_{c 50}^{*}$ would underestimate $D_{B m a x, b f}$ by a factor of more than 2 in the least stable study streams and overestimate $D_{B m a x, b f}$ by more than 3 times in the most stable study streams.

[49] Because bankfull flow depth is used for computing both the noncritical $\tau_{b f 50}^{*}$ and the critical $\tau_{c b f}^{*}$, the impression may arise that $\tau_{b f 50}^{*}$ and $\tau_{c b f}^{*}$ are closely related. However, computation of $\tau_{b f 50}^{*}$ and $\tau_{c b f}^{*}$ differ greatly with respect to the particle sizes used, $D_{50}$ in the first case and $D_{B \text { max }, b f}$ in the latter. As a result, and except for their point of equality in bankfull mobile/stable streams, $\tau_{b f 50}^{*}$ and $\tau_{c b f}^{*}$ are inversely related to bed stability; the ratio of $\tau_{b f 50}^{*} / \tau_{c b f}^{*}$ is near 4 for poorly stable beds (Figure 12) and drops to 0.2 for highly stable beds. Use of $\tau_{b f 50}^{*}$ instead of $\tau_{c b f}^{*}$ to predict the largest bankfull mobile particle size $D_{B \max , b f}$ is therefore a poor option. In the least stable study streams, $\tau_{b f 50}^{*}$ underpredicts $D_{B \max , b f}$ by a factor of four while overpredicting $D_{B \max , b f}$ by fivefold in the most stable study streams.

[50] Estimating $\tau_{c b f}^{*}$ in a variety of steep, coarse streams from a fixed Shields value is not advised. Taking for example the original value near 0.06 [Shields, 1936], the ratio $0.06 / \tau_{c b f}^{*}$ decreases with both bed stability and $S_{x}$ and thus with the associated stream type. For the study streams, a value of 0.06 may be an appropriate estimate for $\tau_{c b f}^{*}$ in plane-bed streams with forced pool-riffle sequences $\left(S_{x}=0.014-0.021 \mathrm{~m} / \mathrm{m}\right)$ under bankfull mobility/stability (Figure 13a). However, 0.06 is less than onetenth of $\tau_{c b f}^{*}$ in the most stable step-pool study streams and would overpredict $D_{B \max , b f}$ there by more than 10 times. Another example is a Shields value of 0.03 that is proposed by Parker [1979] and Parker et al. [2007] for bankfull conditions in low-gradient gravel-bed streams based on hydraulic geometry considerations, and by Parker et al. [2003] for high $R e_{p}$ (actually the explicit Reynolds number $\left.R_{p}=\left(g \cdot\left(\rho_{s}-\rho_{f} / \rho_{f}\right) \cdot D_{50}^{3}\right)^{0.5} / v\right)$, as well as by CIRIA, CUR, CETMEF [2007] for steep earthen dams. A value of 0.03 is a suitable estimate of $\tau_{c b f}^{*}$ in mixed plane-bed/pool-riffle streams $\left(S_{x}=0.01-\right.$ $0.014 \mathrm{~m} / \mathrm{m}$ ) of low bed stability (Figure 13b) but not generally suitable for bankfull mobile/stable streams where $\tau_{c b f}^{*}$ exceeds 0.03 by 1.4 to 7 times depending on stream gradient. Using 0.03 in place of the actual $\tau_{c b f}^{*}$ value for predicting the bankfull mobile particle size $D_{B \max , b f}[$ Kaufmann et al., 2008, 2009] biases the prediction of $D_{B m a x, b f}$
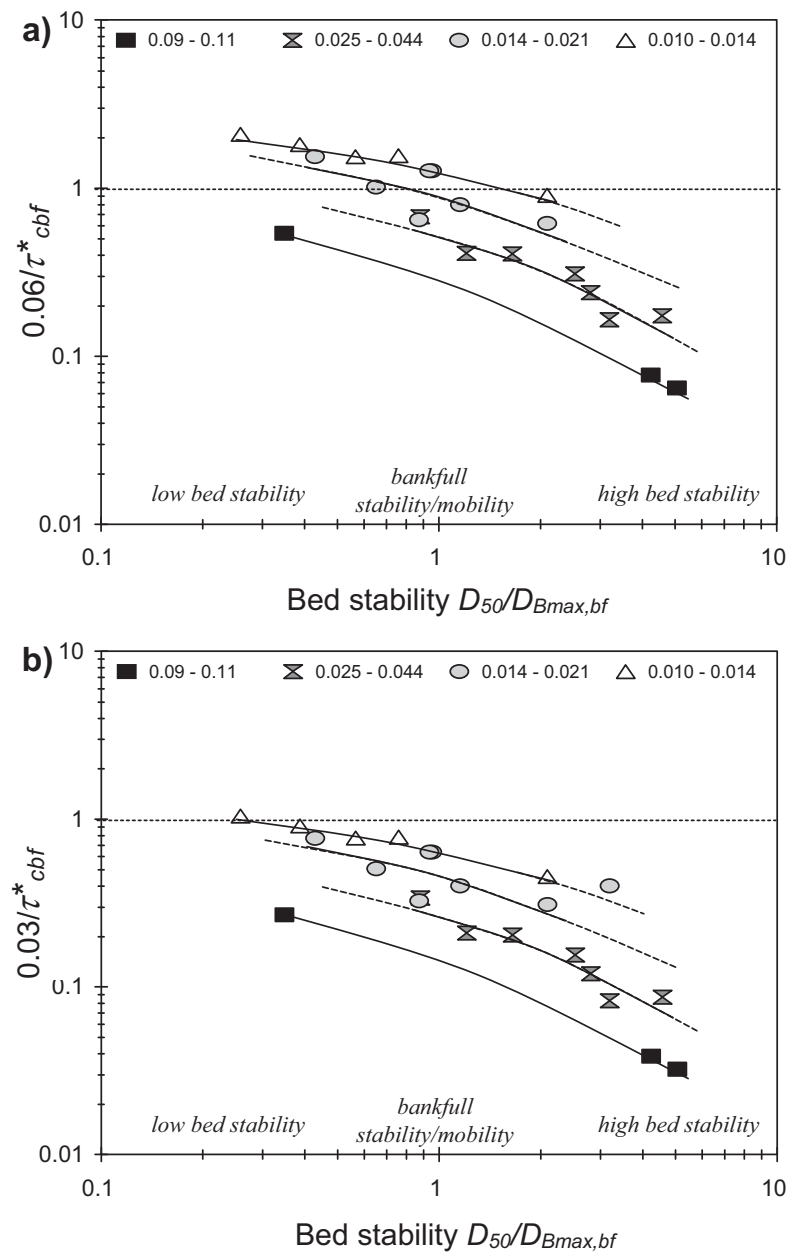

Figure 13. (a) Ratios of $0.06 / \tau_{c b f}^{*}$ and (b) ratios $\tau_{c}^{*}=0.03 / \tau_{c b f}^{*}$, plotted versus bed stability for the study streams and stratified by stream gradient classes. Trendlines are fitted by eye. 
size in all but plane-bed/pool-riffle streams with low bed stability and overpredicts $D_{B \max , b f}$ by as much as 30 times in highly stable step-pool streams. Such mispredictions then introduce considerable errors if bed stability is evaluated from a predicted $D_{50} / D_{B \max , b f}$.

\section{Summary and Conclusions}

[51] Predicting particle mobility in steep gravel-bed streams becomes increasingly important, yet wide scatter of reported $\tau_{c 50}^{*}$ values around the Shields diagram and inter-study variability in relations of $\tau_{c 50}^{*}$ versus stream gradient $S_{x}$ challenge the selection of appropriate Shields values. Prediction of the largest bankfull mobile particle size $D_{B m a x, b f}$ from the Shields approach is especially problematic because Shields values were not designed with that task in mind. This study raised awareness to the differences among Shields values computed for different purposes and from different field and computational methods and to the fact that specific Shields values are required for specific purposes. The study selected field methods which minimize errors in the characterization of bed material and mobile particle sizes, both of which commonly have a high error potential. Based on detailed field data sets, the study used a flow-competence/critical-flow approach to back-calculate critical Shields values $\tau_{c}^{*}$ for various particle sizes and at bankfull flow. The computed values of $\tau_{c}^{*}$ were related to stream gradient and then stratified by various parameters. The resulting relations provide guidance for selecting Shields values suitable for specific applications. Specific study results are listed below.

[52] 1. Average $\tau_{c 50}^{*}$ values for streams with $S_{x}=0.01$ were near 0.05 and increased to 0.2 for $S_{x}$ of 0.1 . The over 6-fold range spanned by individual $\tau_{c 50}^{*}$ values indicates that a single value cannot represent $\tau_{c 50}^{*}$ in steep streams. A positive relation of $\tau_{c 50}^{*}=f\left(S_{x}\right)$ and thus with stream type was confirmed. Stratification by relative depth $\left(d_{b f} / D_{50}\right)$ and relative roughness $\left(D_{84} / d_{b f}\right)$ improved the prediction of $\tau_{c}^{*}$ but was unrelated to stream type. However, it remains unclear whether (or to what degree) the relations of $\tau_{c 50}^{*}$ with $S_{x}, d_{b f} / D_{50}$ and $D_{84} / d_{b f}$ are attributable to numerical artifact or physical processes.

[53] 2. Unexpectedly, $\tau_{c 50}^{*}$ values were not statistically related to bed mobility or stability quantified either by a depth ratio $d_{b f} / D_{50}$ or a grain-size ratio $D_{50} / D_{B m a x, b f}$, suggesting that each stream-type (or each stream gradient class) can experience a wide range of bed mobility, relative depths, and relative roughness at incipient motion. Expanding stream type classifications to include sediment supply and bed stability could advance the relation between critical Shields values and stream morphology.

[54] 3. $\tau_{c 84}^{*}$ values back-computed from critical flows entraining the bed $D_{84}$ size were about half as large as $\tau_{c 50}^{*}$ values, while $\tau_{c 16}^{*}$ values exceeded $\tau_{c 50}^{*}$ by about 3.5 times. The steepness of the relations $\tau^{*}{ }_{c}$ for various particle sizes with $S_{x}$ progressively increased from $\tau_{c 84}^{*}$ to $\tau_{c 16}^{*}$. Again, how much these differences are attributable to numerical artifact or natural processes remains unclear.

[55] 4. Hiding function exponents are positively related to the steepness of the critical flow and negatively related to the steepness of the flow competence curve, hence poorly predictable without a large field study.

[56] 5. Prediction of $D_{B \max , b f}$ requires critical Shields values $\tau_{c b f}^{*}$. $\tau_{c b f}^{*}$ values approximate $\tau_{c 16}^{*}$ when $S_{x} \cong 0.1$ and $\tau_{c 84}^{*}$ when $S_{x} \cong 0.01$, thus spanning an over 30 -fold range. $\tau_{c b f}^{*}$ increases steeply with $S_{x}$; stratification by bed stability $D_{50} / D_{B m a x, b f}$ narrows and explains the scatter. $\tau_{c b f}^{*}$ may be estimated from $S_{x}$ if field evidence permits classification of bed stability as very high, high, bankfull stable, and low. $\tau_{c 50}^{*}$, as well as the noncritical $\tau_{c b f 50}^{*}$ are equal to $\tau_{c b f}^{*}$ at bankfull mobility/stability. $\tau_{c 16}^{*}, \tau_{c 50 s u b}^{*}$, and $\tau_{c 84}^{*}$ may predict $\tau_{c b f}^{*}$ in streams with very high, high, and low bed stability, respectively. Employing $\tau_{c 50}^{*}$ or $\tau_{b f 50}^{*}$ instead of $\tau_{c b f}^{*}$ to estimate $D_{B m a x, b f}$ underpredicts $D_{B \max , b f}$ by 2 or 4 times, respectively, in poorly stable beds and overpredicts by 5 -fold in highly stable streams. Setting $\tau_{c b f}^{*}=0.03$ may predict $D_{B \max , b f}$ in poorly stable streams with $S_{x}$ near 0.01 , but overpredicts $D_{B m a x}$,bf by up to 30 times in highly stable streams with $S_{x}$ near 0.1 .

[57] 6. Bed load samplers that are unsuitable for collecting the largest mobile particles bias collection results and consequently the Shields values computed from them. Helley-Smith derived relations of $\tau_{c}^{*}=f\left(S_{x}\right)$ for the $D_{50 \text { sub }}, D_{50}$, and $D_{84}$ sizes are of similar steepness as those derived from bed load traps, but are 6, 9, and 15\% larger due to undersampling of large bed load particles by the HS and a subsequent overprediction of critical flow. For $S_{x}<0.03$, HS derived $\tau_{c 16}^{*}$ values are smaller than those from bed load traps which reflects the oversampling of midsized particles on finer and shallower beds during lower flows.

[58] 7. Shields values computed from the absolutely largest mobile particle size as opposed to the average largest mobile particle size are systematically lower: $\tau_{c b f}^{*}$ values are halved, and $\tau_{c}^{*}$ values for various particle sizes are reduced by about $25 \%$.

[59] 8. More reliable field data sets of flow competence and other stream parameters from diverse stream environments are desirable to ascertain predictive relations of critical Shields values with stream parameters.

[60] Acknowledgments. We dedicate this paper to John Potyondy (ret., USFS) who initiated the study. We appreciate John's foresight and longterm support of this work. We are grateful to Dieter Rickenmann and Jens Turowski (Swiss Federal Research Institute for Forest, Snow and Landscape, WSL) for giving us access to their gravel bed load data obtained from moving baskets at the Erlenbach. Field data from the studies by Milhous [1973], Whitaker [1997], Hassan and Church [2001], and Schmid [2011] were likewise very useful. Discussions with Tom Lisle, John Buffington, and Peter Wilcock provided food for thought that went into this study. Comments from Mike Church, Alain Recking, Dieter Rickenmann, Rob Ferguson, and an anonymous reviewer helped to improve the manuscript. This study as well as the collection of detailed bed load data over many years was funded by the United States Forest Service Stream Systems Technology Center.

\section{Notations}

$\begin{aligned} A & \text { basin area. } \\ A_{Q} & \text { cross-sectional flow area. } \\ a, c, e, g, i, k & \text { regression coefficients. } \\ b, d, f, h, j, l & \text { regression exponents. } \\ d_{b f} & \text { bankfull flow depth. } \\ d_{c} & \text { critical flow depth for entrainment of an } \\ & \text { unspecified particle size. }\end{aligned}$


$d_{c 50,} d_{c 50 s u b}$ critical flow depth for entrainment of the bed $D_{50}$ and $D_{50 \text { sub }}$ particle sizes.

$d_{c 16}, d_{c 84}$ critical flow depth for entrainment of the bed $D_{16}$ and $D_{84}$ particle sizes.

$D_{B \max }$ average largest bed load particle size, determined from a flow competence curve.

$D_{B m a x, b f}$ average largest bed load particle size at bankfull flow, determined from a flow competence curve.

$D_{c} \quad$ critical, i.e., mobile particle size at specified flow.

$D_{m} \quad$ mean bed material particle size.

$D_{50}$ median bed surface particle size.

$D_{16}, D_{84}$ bed surface particle size of which $16 \%$ and $84 \%$ of the distribution is finer.

$D_{50 \text { sub }}$ median bed subsurface particle size.

$g$ acceleration due to gravity.

$n$ sample size.

$Q_{b f}$ bankfull flow.

$Q_{c} \quad$ critical flow for entrainment of unspecified $D$.

$Q_{c 50}, Q_{c 50 s u b}$

$Q_{c 16}, Q_{c 84}$

$R_{b f}$

$R_{c}$

$R_{c 50}, R_{c 50 s u b}$

$R_{c 16}, R_{c 84}$

$\operatorname{Re}_{p_{2}}$

critical flow for $D_{50}$ and $D_{50 \text { sub }}$.

critical flow for $D_{16}$ and $D_{84}$.

hydraulic radius at $Q_{b f}$.

critical hydraulic radius for unspecified $D$.

critical hydraulic radius for $D_{50}$ and $D_{50 \mathrm{sub}}$.

critical hydraulic radius for $D_{16}$ and $D_{84}$.

Particle Reynolds number $\left(g \cdot R_{c} \cdot S\right)^{0.5} \cdot D_{m} / \nu$.

coefficient of determination.

$s_{y} \quad$ standard error of the $y$ estimate.

$S_{f} \quad$ friction gradient.

$S_{x} \quad$ stream gradient.

$T_{w} \quad$ water temperature.

$v$ mean flow velocity per vertical.

$w$ stream width.

$w_{b f}$ bankfull stream width.

$\beta$ exponent of the hiding function.

$\delta_{s} \quad$ bed material sorting coefficient $\left(\left|\phi_{16}-\phi_{84}\right| / 2\right)$.

$\phi \quad$ grain-size unit; $\phi=-3.3219 \cdot \log (D[\mathrm{~mm}])$.

$\nu$ kinematic viscosity.

$\rho_{f}, \rho_{s} \quad$ densities of water and sediment.

$\tau_{b f 50}^{*}$ noncritical dimensionless shear stress from $Q_{b f}$ and $D_{50}$.

$\tau_{b f, 50 s u b}^{*}$ noncritical dimensionless shear stress from $Q_{b f}$ and $D_{50 s u b}$.

$\tau_{c}^{*} \quad$ critical dimensionless shear stress for unspecified $D$.

$\tau_{c 50}^{*}, \tau_{c 50 s u b}^{*}$ critical dimensionless shear stress for $D_{50}$ and $D_{50 \text { sub }}$.

$\tau_{c 16}^{*}, \tau_{c 84}^{*} \quad$ critical dimensionless shear stress for $D_{16}$ and $D_{84}$.

$\tau_{c b f}^{*} \quad$ critical dimensionless shear stress for $D_{c b f}$.

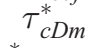

$\tau_{c, l o, e n v}^{*}$ critical dimensionless shear stress for $D_{m}$. critical dimensionless shear stress for $D_{c}$ indicated by the lower envelope of the critical flow curves $Q_{c \text {, low env }}$.

$\tau_{c b f, u p, e n v}^{*}$ critical dimensionless shear stress for $D_{c b f}$ indicated by the upper envelope curves $D_{\text {Bmax,bf,up env }}$.

$\tau_{c H S}^{*} \quad$ critical dimensionless shear stress for unspecified $D$ based on Helley-Smith bed load samples.

\section{References}

Andrews, E. D. (1983), Entrainment of gravel from naturally sorted riverbed material, Geol. Soc. Am. Bull., 94, 1225-1231.

Andrews, E. D. (1994), Marginal bed load transport in a gravel bed stream, Sagehen Creek, California, Water Resour. Res., 30, 2241-2250.

Andrews, E. D., and J. D. Smith (1992), A theoretical model for calculating marginal bedload transport rates of gravel, in Dynamics of Gravel-Bed Rivers, edited by P. Billi et al., pp. 41-52, John Wiley, Chichester, U. K.

Bathurst, J. C., W. H. Graf, and H. H. Cao (1983), Initiation of sediment transport in steep channels with coarse bed material, in Mechanics of Sediment Transport, edited by B. M. Sumer and A. Müller, Proc. Euromech 156, Istanbul, pp. 207-213, Balkema, Rotterdam, The Netherlands.

Bathurst, J. C., W. H. Graf, and H. H. Cao (1987), Bedload discharge equations for steep mountain rivers, in Sediment Transport in Gravel-Bed Rivers, edited by C. R. Thorne, J. C. Bathurst, and R. D. Hey, pp. 453-491, John Wiley, Chichester, U. K.

Beschta, R. L. (1987), Conceptual models of sediment transport in streams, in Sediment Transport in Gravel-Bed Rivers, edited by C. R. Thorne, J. C. Bathurst, and R. D. Hey, pp. 387-419, John Wiley, Chichester, U. K.

Brayshaw, A. C., L. E. Frostick, and I. Reid (1983), The hydrodynamics of particle clusters and sediment entrainment in coarse alluvial channels, Sedimentology, 30, 137-143.

Brownlie, W. R. (1981), Prediction of flow depth and sediment discharge in open channels, Rep. KH-R-43A, 232 pp., W.M. Keck Lab. Hydraul. Water Resour., Calif. Inst. Technol., Pasadena, Calif.

Buffington, J. M. (2012), Changes in channel morphology over human time scales, in Gravel Bed Rivers: Processes, Tools, Environments, edited by M. Church, P. M. Biron, and A. G. Roy, pp. 435-463, John Wiley, Hoboken, N. J., ISBN 9781119952503.

Buffington, J. M., and D. R. Montgomery (1997), A systematic analysis of eight decades of incipient motion studies, with special reference to gravel-bed rivers, Water Resour. Res., 33, 1993-2029.

Buffington, J. M., and D. R. Montgomery (1999), Effects of hydraulic roughness on surface textures of gravel-bed rivers, Water Resour. Res., $35,3507-3521$.

Buffington, J. M., and D. R. Montgomery (2001), Reply to Comment on: "Effects of hydraulic roughness on surface textures of gravel-bed rivers" and "Effects of sediment supply on surface textures of gravel-bed rivers" made by P.R. Wilcock and to Comment on: "Effects of hydraulic roughness on surface textures of gravel-bed rivers" made by R.G. Millar and C.D. Rennie, Water Resour. Res., 37, 1529-1533.

Buffington, J. M., D. R. Montgomery, and H. M. Greenberg (2004), Basinscale availability of salmonid spawning gravel as influenced by channel type and hydraulic roughness in mountain catchments, Can. J. Fish. Aquat. Sci., 61, 2085-2096, doi:10.1139/F04-141.

Buffington, J. M., D. R. Montgomery, and H. M. Greenberg (2006), Erratum: Basin-scale availability of salmonid spawning gravel as influenced by channel type and hydraulic roughness in mountain catchments, Can. J. Fish. Aquat. Sci., 63, 2389, doi:10.1139/F06-143.

Buffington, J. M., B. B. Roper, E. Archer, and C. Moyer (2009), Reply to Discussion by David L. Rosgen "The Role of Observer Variation in Determining Rosgen Stream Types in Northeastern Oregon Mountain Streams". J. Am. Water Resour. Assoc., 45(5), 1298-1312, doi:10.1111/ j.1752-1688.2009.00363.x.

Bunte, K. (1996), Analyses of the temporal variation of coarse bedload transport and its grain size distribution (Squaw Creek, Montana, USA), Gen. Tech. Rep. RM-GTR-288, 123 pp., U.S. Dep. of Agric., For. Serv., Rocky Mt. For. and Range Exp. Stn. Fort Collins, Colo.

Bunte, K. (2012a), Discussion of "Recent advances in the dynamics of steep channels" by F. Comiti and L. Mao, in Gravel Bed Rivers: Processes, Tools, Environments, edited by M. Church, P. M. Biron, and A. G. Roy, p. 374, John Wiley, Hoboken, N. J.

Bunte, K. (2012b), Discussion of "Semi-alluvial channels and sedimentflux-driven bedrock erosion" by J. Turowski, in Gravel Bed Rivers: Processes, Tools, Environments, edited by M. Church, P. Biron, and A. Roy, pp. 374-377, John Wiley, Hoboken, N. J.

Bunte, K., and S. R. Abt (2001a), Sampling surface and subsurface particlesize distributions in wadable gravel- and cobble-bed streams for analysis in sediment transport, hydraulics, and streambed monitoring, Gen. Tech. Rep. RMRS-GTR-74, 428 pp., U.S. Dep. of Agric., For. Serv., Rocky Mt. Res. Stn., Fort Collins, Colo.

Bunte, K., and S. R. Abt (2001b), Sampling frame for improving pebble count accuracy in coarse gravel-bed streams, J. Am. Water Resour. Assoc., 37(4), 1001-1014. 
Bunte, K., and S. R. Abt (2005), Effect of sampling time on measured gravel bedload transport rates in a coarse-bedded stream, Water Resour. Res., 41, W11405, doi:10.1029/2004WR003880.

Bunte, K., and L. H. MacDonald (1999), Scale considerations and the detectability of sedimentary cumulative watershed effects, Tech. Bull. 776, 327 pp., Natl. Counc. of the Pap. Ind. for Air and Stream Impr., Triangle Research Park, N. C.

Bunte, K., S. R. Abt, J. P. Potyondy, and S. E. Ryan (2004), Measurement of coarse gravel and cobble transport using a portable bedload trap, $J$. Hydraul. Eng., 130(9), 879-893.

Bunte, K., K. Swingle, and S. R. Abt (2007), Guidelines for using bedload traps in coarse-bedded mountain streams: Construction, installation, operation and sample processing, Gen. Techn. Rep. RMRS-GTR-191, 91 pp., U.S. Dep. of Agric., For. Serv., Rocky Mt. Res. Stn., Fort Collins, Colo.

Bunte, K., S. R. Abt, J. P. Potyondy, and K. W. Swingle (2008), A comparison of coarse bedload transport measured with bedload traps and HelleySmith samplers, Geodin. Acta, 21(1/2), 53-66.

Bunte, K., S. R. Abt, K. W. Swingle, and J. P. Potyondy (2009), Comparison of three pebble count protocols (EMAP, PIBO, and SFT) in two mountain gravel-bed streams, J. Am. Water Resour. Assoc., 45(5), 1209 1227, doi:10.1111/j.1752-1688.2009.00355.x.

Bunte, K., S. R. Abt, K. W. Swingle, and J. P. Potyondy (2010a), Bankfull mobile particle size and its predictions from a Shields-type approach, in Proc. 4th Fed. Interagency Hydrol. Model. Conf. and 9th Fed. Interagency Sediment. Conf., Advisory Committee on Water Information, [CD-ROM] ISBN 978-0-9779007-3-2.

Bunte, K., S. R. Abt, K. W. Swingle, and J. P. Potyondy (2010b), Functions to adjust transport rates from a Helley-Smith sampler to bedload traps in coarse gravel-bed streams (rating curve approach), in Proc. 4th Fed. Interagency Hydrol. Model. Conf. and 9th Fed. Interagency Sediment. Conf., Advisory Committee on Water Information, [CD-ROM] ISBN 978-0-9779007-3-2.

Bunte, K., K. W. Swingle, and S. R. Abt (2010c), Necessity and difficulties of field calibration of signals from surrogate techniques in gravel-bed streams: Possibilities for bedload trap samples, in Bedload-Surrogate Monitoring Technologies, U.S. Geol. Surv. Sci. Invest. Rep. 2010-5091, edited by J. R. Gray, J. B. Laronne, and J. D. G. Marr, pp. 107-129, Reston, Va.

Bunte, K., K. W. Swingle, J. P. Potyondy, and S. R. Abt (2011), Beaver dam effects on gravel transport patterns: A case study, Abstract EP21C0711 presented at 2011 Fall Meeting, $A G U$, San Francisco, Calif.

Bunte, K., K. Swingle, S. Abt, and J. Potyondy (2012), Bedload traps for sampling gravel/cobble bedload and what we learned from them, Keynote talk, International Workshop Monitoring bedload and debris flows in mountain basins, Free University of Bolzano, Italy [Available at: http://www.unibz.it/EN/SCIENCETECHNOLOGY/WELCOME/ MONITORINGBEDLOADANDDEBRISFLOWSINMOUNTAINBASINS html.]

Camenen, B. (2012), Discussion of "Understanding the influence of slope on the threshold of coarse grain motion: Revisiting critical stream power" edited by C. Parker, N. J. Clifford, and C. R. Thorne, Geomorphology, vol. 126, March 2011, pp. 51-65, Geomorphology, 139-140, 34-38, doi:10.1016/j.geomorph.2011.10.033.

Carling, P. A., A. Kelsey, and M. S. Glaister (1992), Effect of bed roughness, particle shape and orientation on initial motion criteria, in Dynamics of Gravel Bed Rivers, edited by P. Billi et al., pp. 23-36, John Wiley, Chichester, U. K.

Church, M., and M. A. Hassan (2002), Mobility of bed material in Harris Creek, Water Resour. Res., 38(11), 1237, doi:10.1029/2001WR000753.

Church, M., M. A. Hassan, and J. F. Wolcott (1998), Stabilizing selforganized structures in gravel-bed stream channels: Field and experimental observations, Water Resour. Res., 34, 3169-3179.

CIRIA, CUR, CETMEF (2007), The Rock Manual. The Use of Rock in Hydraulic Engineering, 2nd ed., 1302 pp., C683, London.

Comiti, F., and L. Mao (2012), Recent advances in the dynamics of steep channels, in Gravel Bed Rivers: Processes, Tools, Environments, edited by M. Church, P. M. Biron, and A. G. Roy, pp. 353-377, John Wiley, Hoboken, N. J.

Duan, N. (1983), Smearing estimate: A nonparametric retransformation method, J. Am. Stat. Assoc., 87, 605-610.

Fenton, J. D., and J. E. Abbott (1977), Initial movement of grains on a stream bed: The effects of relative protrusion, Proc. R. Soc. London, Ser. A, 352(1671), 523-537.

Ferguson, R. I. (1986), River loads underestimated by rating curves, Water Resour. Res., 22, 74-76.

Ferguson, R. I. (1987), Accuracy and precision of methods for estimating river loads, Earth Surf. Processes Landforms, 12, 95-104.
Ferguson, R. I. (2012), River channel slope, flow resistance, and gravel entrainment thresholds, Water Resour. Res., 48, W05517, doi:10.1029/ 2011WR010850.

Fisher, J. S., B. L. Sill, and D. F. Clark (1983), Organic detritus particles: Initiation of motion criteria on sand and gravels, Water Resour. Res., 19, 1627-1631.

Gomez, B. (1983), Temporal variations in bedload transport rates: The effect of progressive bed-armouring, Earth Surf. Processes Landforms, $8,41-54$.

Gordon, N. D., T. A. McMahon, and B. L. Finlayson (1992), Stream Hydrology: An Introduction for Ecologists, 526 pp., John Wiley, Chichester, U. K.

Halwas, K. L., and M. Church (2002), Channel units in small, high gradient streams on Vancouver Island, British Columbia, Geomorphology, 43, $243-256$.

Hassan, M. A., and M. Church (2000), Experiments on surface structure and partial sediment transport on a gravel bed, Water Resour. Res., 36, 1885-1895.

Hassan, M. A., and M. Church (2001), Sensitivity of bedload transport in Harris Creek: Seasonal and spatial variation over a cobble-gravel bar, Water Resour. Res., 37, 813-825.

Helley, E. J., and W. Smith (1971), Development and calibration of a pressure-difference bedload sampler, USDI, U.S. Geol. Surv. Water Resour. Div. Open File Rep., 18 pp.

Hirsch, R. M., D. R. Helsel, T. A. Cohn, and E. J. Gilroy (1993), Statistical analysis of hydrological data, in Handbook of Hydrology, edited by D. R. Maidment, p. 17.1-17.55, McGraw-Hill, New York.

Inman, D. L. (1952), Measures for describing the size distribution of sediments, J. Sediment. Petrol., 22, 125-145.

Isaak, D. J., W. A. Hubert, and K. L. Krueger (1999), Accuracy and precision of stream reach water surface slopes estimated in the field and from maps, North Am. J. Fish. Manage., 19, 141-148.

Isbash, S. V. (1936), Construction of dams by depositing rocks in running water Transactions, Second Congress on Large Dams, Vol. 5, p. 123-136, Washington, DC.

Kappesser, G. B. (2002), A riffle stability index to evaluate sediment loading to streams, J. Am. Water Resour. Assoc., 38(4), 1069-1081.

Kaufmann, P. R., J. M. Faustini, D. P. Larson, and M. A. Shirazi (2008), A roughness-corrected index of relative bed stability for regional stream surveys, Geomorphology, 99, 150-170.

Kaufmann, P. R., D. P. Larsen, and J. M. Faustini (2009), Bed stability and sedimentation associated with human disturbances in Pacific Northwest streams, J. Am. Water Resour. Assoc., 45(2), 434-459, doi:10.1111/ j.1752-1688.2009.00301.x.

Kellerhals, R., and D. I. Bray (1971), Sampling procedures for coarse fluvial sediments, J. Hydraul. Div., 97(HY8), 1165-1180.

Kirchner, J. W., W. E. Dietrich, F. Iseya, and H. Ikeda (1990), The variability of critical shear stress, friction angle, and grain protrusion in waterworked sediments, Sedimentology, 37, 647-672.

Koch, R. W., and G. M. Smillie (1986), Bias in hydrologic prediction using log-transformed prediction models, Water Resour. Bull., 22(5), 717-723.

Komar, P. D., and Z. Li (1986), Pivoting analysis of the selective entrainment of sediments by shape and size with application to gravel threshold, Sedimentology, 33, 425-436.

Lamb, M. P., W. E. Dietrich, and J. G. Vendetti (2008), Is the critical Shields stress for incipient sediment motion dependent on channel slope? J. Geophys. Res., 113, F02008, doi:10.1029/2007JF000831.

Leopold, L. B. (1994), A View of the River, 298 pp., Harvard Univ. Press, Cambridge, Mass

Lepp, L. R., C. J. Koger, and J. A. Wheeler (1993), Channel erosion in steep gradients, gravel-paved streams, Bull. Assoc. Eng. Geol., 30(4), 443-454.

Li, Z., and P. D. Komar (1986), Laboratory measurements of pivoting angles for application to selective entrainment of gravel in a current, Sedimentology, 33, 413-423.

Lorang, M. S., and F. R. Hauer (2003), Flow competence and streambed stability: An evaluation of technique and application, J. N. Am. Benthol. Soc., 22(4), 475-491.

Mao, L. (2012), The effect of hydrographs on bed load transport and bed sediment spatial arrangement, J. Geophys. Res., 117, F03024, doi:10.1029/2012JF002428.

Meshkova, L. V., P. A. Carling, and T. Buffin-Bélanger (2012), Nomenclature, complexity, semi-alluvial channels and sediment-flux-driven bedrock erosion, in Gravel-Bed Rivers: Processes, Tools, Environments, edited by M. Church, P. M. Biron, and A. G. Roy, p. 424-431, John Wiley, Hoboken, N. J., doi:10.1002/9781119952497.ch31. 
Meyer-Peter, E., and R. Müller (1948), Formulas for bed-load transport, in Proc. Intl. Assoc. Hydraul. Structures Res., 2nd Meeting, Stockholm, p. 39-64, Delft, The Netherlands.

Milhous, R. (1973), Sediment transport in a gravel-bottomed stream, Ph.D. thesis, Oreg. State Univ., Corvallis, Oreg.

Miller, D. M. (1984), Reducing transformation bias in curve fitting, Am. Stat., 38(2), 124-126, doi:10.1080/00031305.1984.10483180.

Miller, M. C., I. N. McCave, and P. D. Komar (1977), Threshold of sediment motion in undirectional currents, Sedimentology, 24, 507-527.

Molnar, P., A. L. Densmore, B. W. McArdell, J. M. Turowski, and P. Burlando (2010), Analysis of changes in the step-pool morphology and channel profile of a steep mountain stream following a large flood, Geomorphology, 124, 85-94.

Montgomery, D. R., and J. M. Buffington (1997), Channel-reach morphology in mountain drainage basins, Geol. Soc. Am. Bull., 109(5), 596-611.

Mueller, E. R., J. Pitlick, and J. M. Nelson (2005), Variation in the reference Shields stress for bedload transport in gravel-bed streams and rivers, Water Resour. Res., 41, W04006, doi:10.1029/2004WR003692.

Neill, C. R. (1968), A reexamination of the beginning of movement for coarse granular bed materials, Rep. no. INT 68, Hydraul. Res. Stn., Wallingford, U. K.

Nelson, P. A., J. G. Venditti, W. E. Dietrich, J. W. Kirchner, H. Ikeda, F. Iseya, and L. S. Sklar (2009), Response of bed surface patchiness to reductions in sediment supply, J. Geophys. Res., 114, F02005, doi: 10.1029/2008JF001144.

Nelson, P. A., W. E. Dietrich, and J. G. Venditti (2010), Bed topography and the development of forced bed surface patches, J. Geophys. Res., 115, F04024, doi:10.1029/2010JF001747.

Olsen, D. S., A. C. Whitaker, and D. F. Potts (1997), Assessing stream channel stability thresholds using flow competence estimates at bankfull stage, J. Am. Water Resour. Assoc., 33(6), 1197-1207.

Paintal, A. S. (1971), A stochastic model of bedload transport, J. Hydraul. Res., 9(4), 527-553.

Parker, C., N. J. Clifford, and C. R. Thorne (2011), Understanding the influence of slope on the threshold of coarse grain motion: Revisiting critical stream power, Geomorphology, 126, 51-65, doi:10.1016/j.geomorph.2010.10.027.

Parker, G. (1979), Hydraulic geometry of active gravel-bed rivers, $J$. Hydraul. Div., ASCE, 105(HY9), 1185-1201.

Parker, G., P. C. Klingeman, and D. G. McLean (1982), Bedload and the size distribution of paved gravel-bed streams, J. Hydraul. Div. Am. Soc. Civ. Eng., 108(HY4), 544-571.

Parker, G., C. M. Toro-Escobar, M. Ramey, and S. Beck (2003), The effect of floodwater extraction on mountain stream morphology, J. Hydraul. Eng., 129(11), 885-895.

Parker, G., P. R. Wilcock, C. Paola, W. E. Dietrich, and J. Pitlick (2007), Physical basis for quasi-universal relations describing bankfull hydraulic geometry of single-thread gravel bed rivers, J. Geophys. Res., 112, F04005, doi:10.1029/2006JF000549.

Pitlick, J., E. R. Mueller, C. Segura, R. Cress, and M. Torizzo (2008), Relation between flow, surface-layer armoring and sediment transport in gravel-bed rivers, Earth Surf. Processes Landforms, 33(8), 1192-1209, doi:10.1002/esp.1607.

Potyondy, J. P., K. Bunte, S. R. Abt, and K. W. Swingle (2010), Bedload movement in mountain channels: Insights gained from use of portable bedload traps, in Proc. 4th Fed. Interagency Hydrol. Model. Conf. and 9 th Fed. Interagency Sediment. Conf., Advisory Committee on Water Information, [CD-ROM] ISBN 978-0-9779007-3-2.

Recking, A. (2009), Theoretical development on the effects of changing flow hydraulics on incipient bedload motion, Water Resour. Res., 45, W04401, doi.1029/2008WR006826.

Recking, A., and J. Pitlick (2013), Shields versus Isbash. J. Hydraul. Eng., 139(1), 51-54, doi:10.1061/(ASCE)HY.1943-7900.0000647.

Reid, I., L. E. Frostick, and J. T. Layman (1985), The incidence and nature of bedload transport during flood flows in coarse-grained alluvial channels, Earth Surf. Processes Landforms 10, 33-44.

Rice, S., and M. Church (1996), Sampling surficial fluvial gravels: The precision of size distribution percentile estimates, J. Sediment. Res., 66(3), 654-665.

Rickenmann, D., J. M. Turowski, B. Fritschi, A. Klaiber, and L. Andreas (2012), Bedload transport measurements at the Erlenbach stream with geophones and automated basket samplers, Earth Surf. Processes Landforms, 37(9), 1000-1011, doi:10.1002/esp.3225.

Roper, B. B., J. M. Buffington, E. Archer, C. Moyer, and M. Ward (2008), The role of observer variation in determining Rosgen stream types in northeastern Oregon mountain streams, J. Am. Water Resour. Assoc., 44(2), 417-427, doi:10.1111/j.1752-1688.2008.00171.x.
Rosgen, D. L. (1994), A classification of natural rivers, Catena, 21, 169-199. Rosgen, D. L. (1996), Applied River Morphology, Wildland Hydrol., Pagosa Springs, Colo.

Rouse, H. (1939), An analysis of sediment transportation in light of fluid turbulence, SCS-TP-25, Sediment Div., U.S. Dep. of Agric., Soil Conserv. Serv., Washington, D. C.

Ryan S. E., L. S. Porth, and C. A. Troendle (2005), Coarse sediment transport in mountain streams in Colorado and Wyoming, USA, Earth Surf. Processes Landforms, 30, 269-288, doi:10.1002/esp.1128.

Schmid, B. (2011), Geschiebetransportuntersuchungen in einem Gebirgsbach. Messungen und Berechnungen für den Riedbach im Kt. Wallis, MS thesis, The Swiss Fed. Inst. Technol. (ETH), Zürich, Switzerland.

Shields, A. (1936), Anwendung der Ähnlichkeitsmechanik und der Turbulenzforschung auf die Geschiebebewegung [Application of similarity principles and turbulence research to bedload movement.], Mitt. Preuss. Ver. Wasserbau Schiffbau, Berlin, Germany, 26, 26 pp.

Shvidchenko, A. B., and G. Pender (2000), Flume study of the effect of relative depth on the incipient motion of coarse uniform sediment, Water Resour. Res., 36, 619-628.

Stelczer, K. (1981), Bed-load Transport. Theory and Practice, Water Resour. Publ., Littleton, Colo.

Swingle, K. W., K. Bunte, and S. R. Abt (2012), Hysteresis in gravel transport rates and particle sizes in mountain streams, poster presented at International Workshop Monitoring Bedload and Debris Flows in Mountain Basins, Free University of Bolzano, Italy [Available at: http://www.unibz.it/EN/SCIENCETECHNOLOGY/WELCOME/ MONITORINGBEDLOADANDDEBRISFLOWSINMOUNTAINBASINS. html.]

Trush, W. J., S. M. McBain, and L. B. Leopold (2000), Attributes of an alluvial river and their relation to water policy and management, Proc. Natl. Acad. Sci. U. S. A., 97(22), 11,858-11,863.

Turowski, J. M. E. M. Yager, A. Badoux, D. Rickenmann, and P. Molnar (2009), The impact of exceptional events on erosion, bedload transport and channel stability in a step-pool channel, Earth Surf. Processes Landforms, 34, 1661-1673.

Turowski, J. M., A. Badoux, and D. Rickenmann (2011), Start and end of bedload transport in gravel-bed streams, Geophys. Res. Lett. 38, L04401, doi: 10.1029/2010GL046558.

Vanoni, V. A., P. C. Benedict, D. C. Bondurant, J. E. McKee, R. F. Piest, and J. Smallshaw (1966), Sediment transportation mechanics: Initiation of motion, J. Hydraul. Div. Am. Soc. Civ. Eng., 92(HY2), 291-314.

Whitaker, A. C. (1997), The initiation of coarse bedload transport in gravel bed streams, Ph.D. Diss., 148 pp., Univ. of Montana, Missoula.

Whitaker, A. C. and D. F. Potts (1996), Validation of two threshold models for bedload initiation in an upland gravel-bed stream, in Watershed Restoration Management: Physical, Chemical, and Biological Considerations, edited by J. J. McDonnell et al., pp. 85-94, Proc. Ann. Symp. Am. Water Resour. Assoc., New York City Water Supply Stud., Syracuse, New York.

Whitaker, A. C., and D. F. Potts (2007a), Coarse bedload transport in an alluvial gravel bed stream, Dupuyer Creek, Montana, Earth Surf. Processes Landforms, 32,1984-2004, doi:10.1002/esp.1512.

Whitaker, A. C., and D. F. Potts (2007b), Analysis of flow competence in an alluvial gravel bed stream, Dupuyer Creek, Montana, Water Resour. Res., 43, W07433, doi:10.1029/2006WR005289.

White, C. M. (1940), The equilibrium of grains on the bed of a stream, Proc. R. Soc. London, Ser. A, 174, 322-338.

Wiberg, P. L., and J. D. Smith (1987), Calculations of the critical shear stress for motion of uniform and heterogeneous sediments, Water Resour. Res., 23, 1471-1480.

Wilcock, P. R. (1988), Methods for estimating the critical shear stress of individual fractions in mixed-sized sediment, Water Resour. Res., 24, 1127-1135.

Wilcock, P. R. (2001), Toward a practical method for estimating sediment transport rates in gravel-bed rivers, Earth Surf. Processes Landforms, 26, 1395-1408.

Yager, E. M., J. W. Kirchner, and W. E. Dietrich (2007), Calculating bed load transport in steep boulder bed channels, Water Resour. Res., 43, W07418, doi:10.1029/2006WR005432.

Yager, E. M., J. M. Turowski, D. Rickenmann, and B. W. McArdell (2012), Sediment supply, grain protrusion, and bedload transport in mountain streams, Geophys. Res. Lett., 39, L10402, doi:10.1029/2012GL051654.

Yalin, M. S., and E. Karahan (1979), Inception of sediment transport, J. Hydraul. Div. Am. Soc. Civ. Eng., 105(HY11), 1433-1443.

Zimmermann, A., M. Church, and M. A. Hassan (2010), Step-pool stability: Testing the jammed state hypothesis, J. Geophys. Res., 115, F02008, doi: 10.1029/2009JF001365. 